
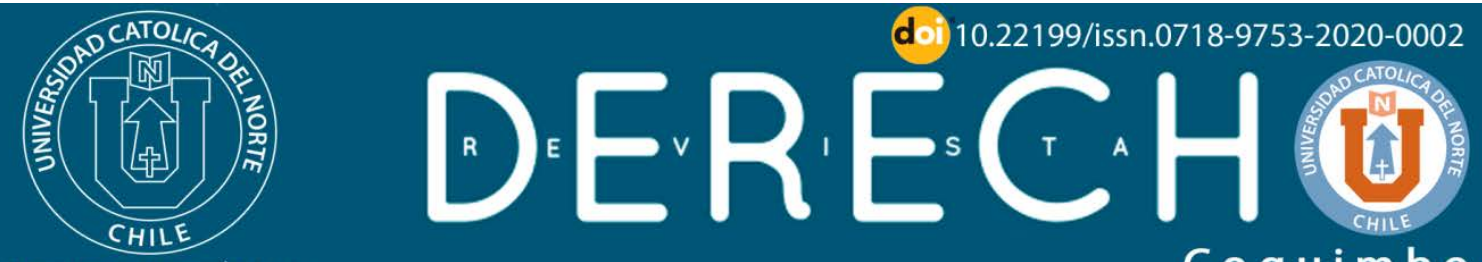

REVISTAS CIENTIIFICAS
de la Universidad Catolica del Nort.

C O q u i m b o

ISSN: 0718-9753 (En línea)

\title{
El daño moral en el contrato de cuenta corriente: un intento de sistematización de la opinión de los tribunales
}

\section{Non pecuniary damages in the bank account contract: an attempt of systematize the judicial decisions}

\author{
Íñigo De la Maza Gazmuri ${ }^{1}$ @ https://orcid.org/0000-0001-6239-2837 \\ Nicolás Montes Serrano² (1) https://orcid.org/0000-0002-8932-9755 \\ 'Universidad Diego Portales, Santiago, Chile. Profesor, Doctor en Derecho. U. Autónoma de Madrid. \\ @inigo.delamaza@udp.cl \\ ${ }^{2}$ Universidad Diego Portales, Santiago, Chile. Profesor Ayudante. \\ @ nicolas.montes@mail.udp.cl \\ (cc) BY
}

\section{Resumen:}

Una de las primeras decisiones judiciales que reconoció, en términos generales, la procedencia de los daños morales frente al incumplimiento contractual fue acerca del incumplimiento de un contrato de cuenta corriente por parte de un banco. En este trabajo consideramos un importante número de sentencias de tribunales superiores sobre el tema e intentamos sistematizarlas con el afán de inducir ciertos criterios que faciliten el siempre espinoso tratamiento de la cuestión en el derecho de contratos.

Palabras Clave: Contrato de cuenta corriente; Incumplimiento; Daño moral; Intereses extrapatrimoniales.

\begin{abstract}
:
One of the first judicial decisions that acknowledged non-pecuniary damages in contract law in general terms was about the breach of a bank account contract. In this paper we consider several judicial decisions and try to systematize them inducting some criteria for dealing with the always thorny issue of non-pecuniary damages in contract law.

Keywords: Bank account contract; Breach of contract; Non-pecuniary damages; Emotional interests.
\end{abstract}




\section{Introducción}

La aceptación abstracta de la procedencia de la indemnización por daño moral frente a incumplimientos contractuales tiene, al menos en lo que se refiere a la opinión de los tribunales superiores de justicia, algo más de dos décadas en Chile. Una de las dos primeras sentencias que la estableció resolvió, precisamente, un caso de incumplimiento por parte del banco de un contrato de cuenta corriente (María Rafart Moutthon con Banco de Chile, 1994).

De allí en adelante, los tribunales han tenido numerosas ocasiones para considerar la cuestión. En este trabajo nos proponemos prestar atención a esas decisiones judiciales. Nuestro objetivo consiste en determinar si es que ha existido un tránsito desde la aceptación abstracta del daño moral en materia de contratos, hacia una concreta que ponga mayor atención en por qué, en ese caso particular, procedía la indemnización del daño moral.

Creemos que el tránsito desde lo abstracto a lo concreto resulta importante pues, como ha sugerido la doctrina más autorizada, del hecho que, en abstracto, se acepte la procedencia del daño moral frente al incumplimiento contractual no ha de seguirse que cualquier incumplimiento contractual justifique esta partida indemnizatoria (Barros Bourie, 2006, pp. 338-339; Domínguez Hidalgo, 2000, p. 305; De la Maza Gazmuri, 2016; Vidal Olivares, 2012).

Ha sugerido también la doctrina que el criterio para determinar si procede o no la indemnización por el daño moral se encuentra en la protección de los intereses que dispensa el contrato 0 , dicho en otras palabras, en la previsibilidad del daño ex artículo 1558 del Código Civil (Barros Bourie, 2006, pp. 343-345).

Teniendo en consideración estas opiniones, en este trabajo examinamos una serie de sentencias de tribunales superiores de justicia sobre incumplimiento del contrato de cuenta corriente por parte del banco, en las que los acreedores han solicitado una indemnización del daño moral. Aunque no estamos seguros de cuan representativa es, la metodología empleada ${ }^{1}$ nos hace suponer que, al menos, no hemos incurrido en una manipulación extremadamente selectiva de los fallos y que algunas conclusiones más o menos generales pueden ser razonablemente inducidas.

A través del examen de esas sentencias, intentamos sistematizar la opinión de los tribunales en procura de criterios que permitan avanzar desde lo abstracto a lo concreto, al menos en esta especie de contrato.

\footnotetext{
1 La metodología de búsqueda se realizó en la página Web de las bases de datos de https://westlawchile.cl; https://www.vlex.com; https://www.microjuris.cl hasta el día 31 de enero del año 2018. Se utilizaron las siguientes palabras claves: "cuenta corriente", "incumplimiento" y "daño moral".
} 
El orden del trabajo es el siguiente. En primer lugar, mostramos las ideas de daño moral abstracto y concreto. A continuación, procuramos dar noticia, en términos panorámicos de las sentencias sobre incumplimiento del contrato de cuenta corriente e indemnización por daño moral. En tercer lugar, presentamos las sentencias que niegan lugar a la indemnización y luego, en cuarto lugar, aquellas que lo conceden. En cada caso ofrecemos un intento de sistematización que se presenta unido y de manera resumida en las conclusiones de este trabajo.

\section{La procedencia de la indemnización por daño moral en abstracto y en concreto}

Históricamente al menos, existe una relación interesante entre la indemnización del daño moral y el contrato de cuenta corriente. Probablemente es la sentencia de la Corte Suprema de 20 de octubre de 1994 (María Rafart Moutthon con Banco de Chile, 1994, cons. 13) la primera que acoge en términos generales -no respecto a tipos especiales de contratos- la procedencia del daño moral frente al incumplimiento de un contrato.

Se trataba del incumplimiento de un contrato de cuenta corriente. Entre enero y agosto de 1985, el banco demandado entregó talonarios de cheques a una persona no autorizada, que los falsificó; por lo demás, la firma con que retiró los talonarios resultaba disconforme con la autorizada por la titular de la cuenta. Varios de esos cheques fueron protestados y la demandante afirma que esta situación le acarreó severos problemas para acceder a instituciones financieras. Continúa la demandante señalando que padeció un daño moral consistente en una lesión a su honor, crédito, prestigio, buen nombre y su desempeño profesional que la afectó profundamente.

El caso llega a la Corte Suprema a través de un recurso de casación incoado por el banco, a través del cual se impugnaba la sentencia de Corte de Apelaciones que le había concedido a la demandante una indemnización por daño moral. La Corte rechazó el recurso de casación advirtiendo, de una parte, que la negligencia del banco era causa del daño padecido por la demandante. Por otra, señaló que procedía el daño moral.

Los argumentos fueron los siguientes. En primer lugar, el artículo 1556 del Código Civil no impide la indemnización del daño moral en materia contractual y que menos puede afirmarse que dicho daño está prohibido en sede contractual; por lo demás, añade la Corte, los bienes extrapatrimoniales como el honor y la fama tienen un valor que de ordinario supera a los patrimoniales. En segundo lugar, indica la sentencia que la Corte ya había acogido antes la partida del daño moral, en una sentencia de 3 de julio de 1951 y en otra de 14 de abril de 1954 dicho daño. A continuación, se refiere la sentencia a la Carta Fundamental, específicamente a la protección 
que en el numeral 4 del artículo 19, a la Declaración Americana de los Derechos del Hombre y al Pacto de San José de Costa Rica. En cuarto lugar, la sentencia se refiere a la aceptación del daño moral en el derecho extranjero.

Pues bien, estos argumentos, confirmados y expandidos más tarde en una sentencia de la Corte Suprema de 5 de noviembre de 2001 (Hugo Ruiz Ruiz con Laboratorio Biológico SA; Laboratorio de Especialidades Bionuclear SA; Laboratorio Bionuclear SA; Alejandro Guiloff Caro; Instituto de Salud Pública de Chile; Fisco de Chile, 2001), por así decirlo, pavimentaron jurisprudencialmente la aceptación del daño moral frente a casos de incumplimiento contractual.

Se trata, sin embargo, de una pavimentación a nivel abstracto. Es decir, lo que la Corte resolvió en ambos casos y, básicamente, con los mismos argumentos, es que en el ámbito nacional no existen inconvenientes para que frente a un caso de incumplimiento contractual proceda una indemnización por daño moral. Sin embargo, la Corte no señala por qué en esos casos concretos procedería la indemnización del daño moral.

Esta omisión, probablemente, no resulte tan perceptible en el caso resuelto por la Corte en la sentencia del 5 de noviembre de 2001. En los hechos, una persona acudió a un laboratorio para realizarse el test de Elisa del VIH. El examen arrojó que la persona estaba contagiada. El resultado fue ratificado por el Instituto de Salud Pública. Más de dos años después, la misma persona se realizó un nuevo examen en otro centro médico. El nuevo examen determinó que no padecía la enfermedad.

Es probable que el dramatismo del caso aligerara la necesidad de justificar por qué en ese caso en concreto procedía la indemnización del daño moral. A lo anterior, probablemente deba agregarse -y sobre esto volveremos después- que resulta bastante previsible que el incumplimiento de este contrato lesione intereses extrapatrimoniales.

Sin embargo, en el caso del incumplimiento del contrato de cuenta corriente las cosas no resultan tan evidentes. No parecen existir dudas acerca de que el incumplimiento por parte del banco generará molestias al cuentacorrentista; pero, es igualmente notorio que casi cualquier incumplimiento contractual genera algún tipo de molestias. Lo que, desde luego, no es nada evidente es que cualquier incumplimiento obligue a indemnizar el daño moral. Por otra parte, a simple vista, el contrato de cuenta corriente, con un contenido marcadamente patrimonial, no parece involucrar con la misma intensidad que los contratos de servicios médicos bienes de carácter extrapatrimonial. Evidente muy seguido. 


\section{Una mirada panorámica a las sentencias de los tribunales superio- res sobre contrato de cuenta corriente en que se solicita la indemni- zación del daño moral}

Con posterioridad a la sentencia del 20 de octubre de 1994, la Corte Suprema ha tenido numerosas oportunidades para pronunciarse respecto de la indemnización del daño moral frente al incumplimiento del banco, no consideramos aquí casos extremadamente interesantes resueltos por los tribunales superiores de justicia en que un tercero, sin autorización, abre una cuenta a nombre de otra persona que luego utiliza. La razón es que no se trata de casos de responsabilidad contractual, sino extracontractual como ha tenido oportunidad de fallarlo la Corte de Apelaciones de Santiago el 1 de Septiembre de 2003 (Soto con Banco Santander, 2003), el 26 de octubre de 2011(Velasco Morandé Alfredo c. Corpbanca, 2011) y la Corte Suprema el 24 de abril de 2012 (Julián García Galleguillos con Banco del Desarrollo, 2012), el 9 de septiembre de 2015 (Kim Jong Hyun con Banco Santander Chile, 2015) y el 12 de mayo 2016 (Enrique Miñano Zenteno con Banco Santander Chile y otro, 2016).

Los incumplimientos quedan configurados por diversas acciones $u$ omisiones del banco. Así, por ejemplo, la entrega de talonarios de cheques a una persona no autorizada por la cuentacorrentista (María Rafart Moutthon con Banco de Chile, 1994, cons. 2), el no pago y protesto de un cheque por firma disconforme cuando la firma correspondía (Sociedad Educacional Colegio Alemán de Arica Limitada y otra con Banco del Estado de Chile , 2011; Urrutia Aguilera Eleodora con Banco Estado, 2012), protesto indebido de cheques por cuenta cerrada incorrectamente (Enrique Le Dantec Gallardo con Banco de Chile, 2007, p. 9; Juan Luis Arellano Vaillant con Banco Santiago, 2007, p. 5), por protesto indebido por incorrecta designación del girador (María Gloria Quintana Seguel con Banco de A. Edwards, 2008, p. 12), por un cargo incorrecto de más de $\$ 42.000 .000$ en la cuenta corriente (Banco Santander contra, 2009) o de $\$ 187.840$ (Meriño Figueroa, Marcos Atilio con Banco Santander Santiago, 2010), por protesto de un pagaré vencido (Julio Fritz Vidal con Banco Santander Chile, 2011), por extravío de bonos que el banco debía cobrar a ISAPRES (Testar y Compañía Limitada c. BBVA Banco $B H I F, 2011)$, violación de sistemas de seguridad que permiten a terceros inmiscuirse en la cuenta del titular y extraerle cuantiosos fondos (Méndez Soto Pablo con Banco de Chile, 2012), el cobro de dividendos hipotecarios inexistentes (Olivi Melendez con Banco Santander Chile, 2012), por las dificultades para cerrar la cuenta corriente (Sara Echeverría Zárate con Banco Santander Chile, 2014), por término indebido del contrato (Víctor Mena Lobos con Banco Santander, 2016), etc.

Junto a estas sentencias, encontramos otras tantas de cortes de apelaciones sobre incumplimiento del contrato de cuenta corriente por parte de los bancos. Así, a modo ejemplar, el protesto de dos cheques en donde existían fondos para pagarlos (Juan Bautista Bustos Ortega con Banco Santander Santiago, 2005, cons. 3), la indebida 
carga de la deuda de la tarjeta de crédito a la cuenta corriente del cliente (Juan Luis Arellano Vaillant con Banco Santiago, 2005), la consignación en el acta de protesto de un domicilio distinto al registrado (Erick Daniel Ulriksen Schmidlin con Banco de Crédito e Inversiones $B C l, 2009$ ), el cobro de mantención que se solicitó su cierre (Mabel Cruz Muñoz con Banco Santander Chile, 2013), el sufrimiento de un fraude informático que conlleva la sustracción del dinero de la cuenta (Gloria Cofian Huenchulaf con Banco Estado Chile, 2013; Oscar Mahuzier García con Corpbanca, 2015), la entrega de tarjetas asociadas a la cuenta a un tercero (Víctor Hugo Rivera Castro con Banco Santander Chile, 2015, cons. 14), por el protesto en razón de la inexistencia de la cuenta (Dagoberto Zavala Jiménez con Banco de Crédito e Inversiones, 2015), el protesto de un cheque y el posterior envió a Dicom (Sociedad Agrícola y Forestal Casa Blanca Ltda. con Banco Santander Chile, 2001), el traspaso de dinero por parte de un tercero a su propia cuenta (Miguel Thomson San Martín con Banco Sudamericano, 2007), el protesto de dos cheques que se encontraban caducados (Rol $N^{\circ} 1419-2009$ ), la reserva de una compra internacional (Importadora y Exportadora Sha Sha Limitada con Banco Santander Chile, 2013), el no cierre de una cuenta, que genera una deuda y envió al registro de deudores morosos (Carlos González Escobar con Corpbanca, 2014), la sustracción de dinero de la cuenta a través de cajeros automáticos (Lilia Leguías Ibarra con Banco de Chile, 2014), etc.

Considerando las sentencias de la Corte Suprema, encontramos que en 16 casos se concede una indemnización por daño moral. Las restantes 6 no. Por lo que toca a las sentencias de las cortes de apelaciones, encontramos 18 que conceden esta partida indemnizatoria y 9 que le niegan lugar.

\section{La pregunta que suscita esta situación}

En principio, no hay nada extraño en que, en ocasiones, la Corte haya concedido la indemnización por daño moral y, en otras le haya negado lugar. Después de todo, aunque en todos los casos se trate de contratos de cuenta corriente, las circunstancias -incluyendo en ellas la forma de incumplimiento y sus consecuenciaspueden ser muy diversas.

La pregunta que nos interesa considerar a propósito de las sentencias de la Corte Suprema, se relaciona con el tránsito desde la aceptación en abstracto del daño moral frente al incumplimiento contractual hacia una aceptación en concreto que se haga cargo, argumentativamente, de las circunstancias particulares del caso.

Nos parece que esta pregunta resulta interesante, pues la doctrina parece estar de acuerdo en que no todo incumplimiento contractual origina el deber de indemnizar el daño moral. De esta manera, según una opinión especialmente autorizada, la de la profesora Carmen Domínguez: 
... aunque aboguemos por un claro reconocimiento del daño moral en esta esfera [la contractual] de la responsabilidad, creemos que ello no ha de suponer ni supone una indebida aplicación del ámbito del contrato que pueda conducirnos a una verdadera fantasía contractual. No se trata ciertamente de conceder esta índole de reparación por consecuencias no económicas remotas que de ninguna manera han podido entrar en el cálculo de riesgos del deudor. La infracción del contrato supone siempre molestias y desagrados, pero ello no significa que éstos puedan y deban ser indemnizados como daño moral. Por el contrario, sólo debe ser resarcido por vía contractual el perjuicio extrapatrimonial producido a resultas del incumplimiento y no ocasionalmente por él... (Domínguez Hidalgo, 2000, p. 355)

Por su parte, Barros Bourie (2006) ha sugerido que:

Todo indica que lo determinante para que proceda la reparación por daño moral por incumplimiento contractual es el ámbito de intereses protegidos por el contrato. Por lo mismo, la discusión acerca de la procedencia del daño moral en materia contractual conduce a una pregunta clásica de la responsabilidad contractual: ¿pertenece ese daño preciso al ámbito de riesgo del contrato; o, lo que es lo mismo, ¿pudieron las partes, al tiempo del contrato, prever razonablemente que del incumplimiento se derivarían para el acreedor los perjuicios morales que ahora demanda?. (p. 337)

Opiniones semejantes ese pueden encontrar en Jana Linetzky y Tapia Rodríguez (2004); De la Maza Gazmuri (2016, p. 569) y; Vidal Olivares (2012, p. 646).

En tercer lugar, comentando una sentencia de la Corte Suprema de 3 de enero de 2000, Domínguez Águila (2000) estima también que lo determinante consiste en precisar el "estricto ámbito contractual" (p. 175). Sirviéndose de la distinción entre contratos personales y comerciales concluye:

Un contrato de representación de una empresa productora de armamento y su ejecución por parte del representante no parece, en caso alguno, que pueda comprender dentro de su 'ámbito' la consideración de intereses o situaciones no económicas en aquel sentido y que puedan ser 'consecuencias virtualmente comprendidas en él', de modo que es imposible pretender que la falta de pago de las comisiones previstas pueda generar un daño moral. (Domínguez Águila, 2000, p. 176)

Pues bien, puestas de esta manera las cosas parece ser el caso que (1) no todo incumplimiento contractual genera la obligación de indemnizar el daño moral, (2) Para decidir en qué casos procede es necesario atender al ámbito de protección del contrato y (3) para delimitar ese ámbito parece conveniente precisar si se trata de un contrato comercial o personal.

Si esto es correcto, una primera pregunta que convendría formularse es si el contrato de cuenta corriente tiene el carácter de comercial o personal. La respuesta a esta pregunta depende de qué se entienda por comercial y qué por personal o, dicho 
de otra manera, cuáles son los criterios que permiten encasillar un contrato en una u otra categoría.

Hasta donde llegan nuestras noticias, la cuestión no ha sido considerada con atención por la doctrina nacional. Es probable que existan contratos que pueden encasillarse sin problemas en una u otra categoría. Así, probablemente un contrato de venta de acciones entre dos empresas tenga un carácter netamente comercial y algunos de prestaciones médicas uno netamente personal. Sin embargo, otros tienen más bien un carácter mixto. Así, por ejemplo, en el ámbito estadounidense se ha estimado respecto de ciertos contratos de seguro de responsabilidad que si bien, poseen un innegable aspecto patrimonial, se ha entendido que, a la vez, pueden tutelar intereses extrapatrimoniales (Goldberg, 1986).

Muy probablemente con el contrato de cuenta corriente suceda, en general, lo mismo. Por esta razón, resulta igualmente probable que la estrategia de distinguir entre contratos comerciales y personales no resulte totalmente adecuada para decidir si procede o no el daño moral (Una crítica en general al uso de esta distinción en; Goldberg, 1986, p. 67).

Lo que queda, entonces, es prestar atención al ámbito de protección del contrato y determinar si cubre o no intereses extrapatrimoniales. Nuestra intención consiste en determinar si los tribunales hacen algo como esto cuando resuelven peticiones de indemnización de daño moral frente al incumplimiento del contrato de cuenta corriente.

Si lo hacen, debería ser perceptible tanto en las sentencias que rechazan la indemnización del daño moral como en aquellas que lo acogen.

\section{Las sentencias que niegan la indemnización por daño moral}

Según nuestra lectura de las sentencias, las razones por las cuales los tribunales no conceden la indemnización del daño moral pueden dividirse en tres grupos. El primero de ellos se refiere a cuestiones generales, propias de la responsabilidad civil en general que no contribuyen al objeto de este trabajo. ${ }^{2}$ El segundo grupo desecha

\footnotetext{
${ }^{2}$ En primer lugar, en alguna ocasión, los tribunales han estimado que existiría algún problema de incompetencia absoluta del tribunal ante el cual se demanda la indemnización. En este sentido, una sentencia dictada Corte de Apelaciones de Iquique (Importadora y Exportadora Sha Sha Limitada con Banco Santander Chile, 2013) que resuelve que la ley 19.496 no es aplicable al caso, toda vez que el demandante no cumple con el requisito del articulo 2 letra a), al no ser un acto civil para él, sino que mercantil. En segundo lugar, encontramos sentencias en las cuales los tribunales estiman que no ha existido incumplimiento por parte del Banco. Así, en una sentencia de Corte de Apelaciones de Santiago de Santiago (Lilia Leguías Ibarra con Banco de Chile, 2014) resolvió que no se ha incumplido la obligación de seguridad del contrato, porque el Banco demandado no está obligado a tener cámaras de seguridad en todos los cajeros automáticos del país, incluyendo los que no son de su propiedad. Por otra parte, en una sentencia de la primera sala de la Corte Suprema del 27 de febrero de 2017 (Carmen Aravena Cerda con Banco de Chile, 2017), en donde la Corte estima que el protesto por falta de
} 
las indemnizaciones por falta de prueba. Por último, el tercer grupo se refiere a la previsibilidad del daño.

\subsection{La cuestión de la prueba}

Nos interesa considerar cinco sentencias que desechan la procedencia del daño moral por falta de prueba.

La primera de ellas es la sentencia de la Corte de Apelaciones de Valdivia de 2 de octubre de 2001 (Sociedad Agrícola y Forestal Casa Blanca Ltda. con Banco Santander Chile, 2001, cons. 1) en el que el Banco, erróneamente, envió, para su publicación en el Boletín de Informaciones Comerciales, una constancia de protesto por falta de fondos de una sociedad. La Corte señala que la sentencia del tribunal de instancia, que había concedido a una sociedad una indemnización por daño moral de $\$ 35.000 .000$ "no individualiza ni describe cuál es su derecho extrapatrimonial perjudicado" y rechaza la indemnización por daño moral.

Sobre la sentencia, debemos prestar atención a los considerandos 8 y 9 de la sentencia:

8. Que la prueba del daño moral corresponde al que lo alega y necesariamente debe establecerla de manera que no haya duda alguna sobre su real existencia, siendo improcedente presumirlo por el posible desprestigio derivado de una imputación equivocada concerniente al incumplimiento de una obligación.

fondos y posterior envío de información al Boletín de Informes Comerciales se encontraba plenamente justificado, toda vez que la misma usuaria había retirado el dinero de la cuenta con un mes de anticipación, no siendo posible alegar que existían fondos en ella. Finalmente, en la sentencia del 30 de julio de 2012, la Corte Suprema (Urrutia Aguilera Eleodora con Banco Estado, 2012) estimó que no existía incumplimiento en el protesto de un cheque por una firma que resultaba visiblemente disconforme. En tercer lugar, en dos ocasiones los tribunales han negado la procedencia de las indemnizaciones por daño moral por estimar que el vínculo de causalidad no se encuentra suficientemente acreditado. El primero de ellos corresponde a una sentencia de la Corte de Apelaciones de Concepción (Rol No 1419-2009), que rechaza la demanda que solicitaba el daño moral por el protesto de dos cheques que se encontraban caducados. La Corte señala que no es posible acreditar que los daños morales provienen necesaria y directamente de los dos cheques, toda vez que la actora presentaba protestos de cheques anteriores y posteriores a los alegados. El segundo de los casos corresponde a una sentencia de la Corte de Apelaciones de Santiago (Miguel Thomson San Martín con Banco Sudamericano, 2007), negó la demanda de daño moral, debido a que la verdadera causa del daño sufrido por el demandante no fue el actuar del Banco, si no que fue la exposición imprudente al daño por él mismo, ya que entregó las claves secretas a un tercero, siendo este quien abuso de la confianza depositada en él. En cuarto lugar, en el caso de Sara Echeverría Zárate con Banco Santander Chile (2014), se estimó que no procede conceder indemnización, toda vez que la demandante no individualizó las partidas indemnizatorias que quería resarcir, ni tampoco sus montos específicos. En quinto lugar, la sentencia del 23 de julio de 2008 la Corte Suprema (María Gloria Quintana Seguel con Banco de A. Edwards, 2008) rechaza el recurso por no influir sustancialmente en el fallo. En sexto lugar, la Corte Suprema (Méndez Soto Pablo con Banco de Chile, 2012) , toda vez que el tribunal de primera como la Corte de Apelaciones respectiva, señalaron como hecho de la causa que la transferencia se había realizado por una persona que tenía autorización para hacerlas, no pudiendo por tanto modificarlo.

Rev. derecho (Coquimbo, En línea) 2020, 27: e4093 
9. Que constituyendo la existencia del daño moral un requisito básico para acoger la indemnización del perjuicio reclamado por ese concepto resulta impropio dar lugar a la acción indemnizatoria si dicho perjuicio no se ha probado. (Sociedad Agrícola y Forestal Casa Blanca Ltda. con Banco Santander Chile, 2001, cons. 8 y 9)

A esto tendremos que añadir que el considerando 10 de la sentencia señala:

Que por otra parte, no puede desconocerse que las imputaciones injuriosas contra el honor sólo dan derecho a indemnización pecuniaria si se acredita daño emergente o lucro cesante, conforme previene el artículo $2.331 \mathrm{del}$ Código Civil, situación que no corresponde a la de autos, ya que según el fallo en alzada cuyo criterio la Corte comparte en este punto, no está acreditado en el juicio, circunstancia que igualmente orienta a desestimar la indemnización por daño moral que se exige. (Sociedad Agrícola y Forestal Casa Blanca Ltda. con Banco Santander Chile, 2001, cons. 10)

Siguiendo un orden cronológico, la segunda sentencia es de la Corte de Apelaciones de Santiago de fecha 29 de abril de 2004 que resuelve un caso de pago de 18 cheques con firma disconforme de cheques, no concede la indemnización por daño moral solicitada pues entiende que: "En cuanto al daño moral, prueba alguna hay en autos que permita sostener que el demandante ha sufrido un menoscabo psicológico con el incumplimiento del demandado, razón por la cual se desestimará la demanda en dicha parte" (Gana Eguiguren, Juan Pablo con Banco Santiago, 2004, cons. 10).

Una tercera sentencia a las que nos interesa poner atención corresponde a la de la Corte de Apelaciones de Santiago de 18 de mayo de 2010. Se trata de un caso en el que se cobró de la cuenta corriente del demandante la cuota de un préstamo que ya se había pagado por caja. El banco se demoró una semana en reversar la cantidad y se alegó daño moral por esta circunstancia. La Corte lo rechazó argumentando lo siguiente:

40) Que en lo que concierne a la demora en reversar el cargo efectuado sin la advertencia de que la cuota de que se trataba ya había sido pagada 2 días antes, tampoco se acreditó un real y efectivo perjuicio que se manifestara en cobro de intereses o en alguna otra forma. Y la semana de demora en retrotraer las cosas al estado en que estaban hasta el momento del cargo en la cuenta corriente, no justifica en el sentir de estos sentenciadores una indemnización por daño moral, porque no es de presumir un daño de tal intensidad que merezca dicha calificación y de lugar a un resarcimiento que busca compensar lo que no se puede corregir. (Rol N527-2010, cons. 4)

La cuarta sentencia que nos ocupa es la de la Corte de Apelaciones de Concepción de 4 de junio de 2010. El Banco demandado protestó dos cheques de la cuenta corriente de la actora, uno por falta de fondos y otro por orden de no pago, en circunstancias que ambos se encontraban caducados. Señaló la demandante que esta situación "... se tradujo en un menoscabo para su actividad comercial que le produ- 
jo una lesión de interés moral" (Citado en Rol N 1419-2009, cons. 2). La Corte consideró que el daño no se encontraba acreditado. Estimó que resultaba importante advertir que la autora registraba protestos publicados antes y después de los que reprochaba al banco. Por lo mismo, no parecía razonable considerar que los cheques protestados por el banco fueran la causa de los males que alegaba haber padecido.

La sentencia cita a su favor los siguientes considerandos de una sentencia de la Corte Suprema, Rol №6167-2007:

SEXTO: Que, en este ámbito, el daño, sea material o moral, debe estar debidamente acreditado. Ello, pues todo incumplimiento contractual supone necesariamente molestias o desagrados, lo que no significa que éstos deben ser indemnizados como menoscabo moral, si no se ha producido un efectivo agravio a un derecho subjetivo, el cual deberá explicitarse, sin que en materias como la que nos ocupa, ello se presuma. En este orden de ideas, el destacado jurista nacional Fernando Fueyo Laneri enseña que 'todo daño debe probarse, sea patrimonial, sea extrapatrimonial. El método y el objeto sobre que recae la prueba, y su extensión, serán diferentes según la clase de daño; pero esa es una cuestión aparte y no hace excusable la prueba que se ha de rendir en todo caso' (Instituciones de Derecho Civil Moderno, Editorial Jurídica de Chile, año mil novecientos noventa, páginas 105 y 106). En consecuencia, sólo es indemnizable el daño probado. En otros términos, no puede condenarse a la reparación de los perjuicios morales causados por el incumplimiento contractual, si éstos no se hallan acreditados ante el tribunal que conoce del proceso. SÉPTIMO: Que no existen en nuestro derecho normas especiales sobre la prueba del daño moral, por lo que rigen sin contrapeso las reglas generales. Es por ello que, por lo pronto, para que el perjuicio moral sea indemnizable, se requiere, como ocurre con todo daño, que sea cierto o real y no meramente hipotético o eventual, acreditándose el agravio, la certeza y realidad del mismo, su entidad y magnitud y las consecuencias que de él se han derivado. Si bien son ciertas las dificultades que entraña probar el daño moral, dado que por sus propias características no es posible contar con una prueba directa, es menester, en todo caso, acreditar hechos de los cuales puedan inferirse, al menos, la lesión de carácter extrapatrimonial que ha sufrido el afectado, o bien la falta de oportunidades que producto del hecho se le ha generado a la víctima. (Citado en Rol $N^{\circ} 1419-2009$, cons. 1)

La quinta sentencia que nos interesa presentar corresponde a la de la Corte de Apelaciones de Valparaíso de 11 de junio de 2014. En ella se resolvió que el banco había sido negligente en cerrar la cuenta del actor, generándose una deuda que, en definitiva, determinó que apareciera en un registro de deudores morosos. La Corte rechaza la indemnización por daño moral solicitada con el siguiente argumento:

Noveno: Que, al margen de lo anterior, tal como se establece en la sentencia recurrida, lo cierto es que efectivamente la demanda hace consistir su pretensión de daño moral en la circunstancia de haberse informado supuestas morosidades al Boletín Comercial que mantiene DICOM y que ello le habría 
implicado consecuencias dañosas ante instituciones comerciales, como asimismo le habría afectado su calidad de empleado público de la Armada de Chile, en circunstancias que, según lo que ya se ha indicado a propósito de los considerandos decimoctavo a decimonoveno de la sentencia recurrida, no se ha rendido prueba que sostenga suficientemente las alegaciones de la demandante.

Décimo: Que, finalmente, claro está que el daño moral, como todo hecho, debe ser debidamente acreditado y si bien existen situaciones en que el juzgador puede concluirlo a través del medio probatorio constituido por las presunciones, no es el caso de la especie. (Carlos González Escobar con Corpbanca, 2014, cons. 9 y 10)

Estas cinco sentencias nos provocan un par de comentarios. El primero de ellos tiene que ver con el hecho de que un incumplimiento contractual debe lesionar un interés extrapatrimonial para originar una indemnización por daño moral.

Por supuesto se trata de algo trivialmente obvio. Sin embargo, al examinar las sentencias descubrimos algún matiz que puede resultar menos evidente. Creemos que este conjunto de sentencias desecha la idea de una conexión automática entre el incumplimiento del contrato de cuenta corriente y la procedencia de una indemnización por daño moral ${ }^{3}$.

Esta idea podría desenvolverse de la siguiente manera. Por regla general un incumplimiento contractual provocará un cierto malestar o desagrado en el acreedor, este desagrado o malestar constituye un daño moral que debe ser indemnizado (Kramer, 2014, pp. 504-506).

Con todo, en la sentencia de la Corte de Apelaciones de Valdivia de 2 de octubre de 2001 (Sociedad Agrícola y Forestal Casa Blanca Ltda. con Banco Santander Chile, 2001, cons. 9) en el que el Banco, erróneamente, envió, para su publicación en el Boletín de Informaciones Comerciales, una constancia de protesto por falta de fondos de una sociedad, se rechazó la indemnización por daño moral pues no se había individualizado ni descrito el derecho extrapatrimonial perjudicado. Se trataba de una sociedad y esto complica las cosas pues resulta extremadamente discutible la procedencia del daño moral tratándose de personas jurídicas con fines de lucro (Ver discusión en Barros Bourie, 2006, pp. 297-301), sin embargo, no nos parece que el simple malestar que se experimenta por un incumplimiento contractual pueda considerarse como un derecho extrapatrimonial perjudicado.

La sentencia es de la Corte de Apelaciones de Santiago de fecha 29 de abril de 2004 sobre el pago de 18 cheques con firma disconforme de cheques, estimó que no

\footnotetext{
${ }^{3}$ Sin embargo, como nos hecho ver uno de los árbitros de este trabajo, también se puede sostener que las sentencias en estos casos sí consideraron procedente el daño moral pero no lo indemnizan porque no fue probado en ese proceso. Es decir, si hubiera sido probado, habrían condenado sin importar si había o no conexión entre el incumplimiento y la lesión a un interés extrapatrimonial.
} 
existía prueba en los autos que permitiera sostener que el demandante hubiera sufrido un menoscabo sicológico con el incumplimiento del demandado. Creemos que, al igual que en la sentencia anterior, lo que la Corte exige bajo la expresión "menoscabo sicológico" (Gana Eguiguren, Juan Pablo con Banco Santiago, 2004, cons. 10) es algo distinto y más intenso que el inevitable $y$, muy probablemente, intenso desagrado que, presumiblemente, debe haber experimentado el cuentacorrentista.

Una sentencia de la Corte de Apelaciones de Valparaíso de 26 de septiembre de 2011 (Aotearoa Servicios e inversiones LTDA. Con Banco de Crédito e inversiones, 2011), en donde se le reprocha al banco el pagar 8 cheques que fueron falsificados por terceros, cargándolos a la cuenta corriente del demandante. Sobre el daño moral, estima no que existió prueba suficiente tanto para el daño extrapatrimonial alegado para el representante legal, como para la propia persona jurídica.

Esta misma idea se repite con mayor intensidad en la sentencia de la de la Corte de Apelaciones de Santiago de 18 de mayo de 2010 (Rol N527-2010, cons. 4). Como se recordará, allí se demandó daño moral por el malestar que le produjo al demandante el hecho de que el banco se demorara una semana en reversarle una cantidad de dinero que ya había pagado. En este caso, la Corte advierte que ese supuesto daño ni siquiera merece la calificación de daño moral.

La misma idea -es decir que el simple malestar que provoca el incumplimiento contractual no corresponde a daño moral- ha sido repetida por sentencias de cortes de apelaciones respecto de otras cuestiones en múltiples ocasiones. Así, por ejemplo, en tres sentencias relativamente recientes de la Corte de Apelaciones se lee lo siguiente:

... tampoco existe en la especie, prueba alguna tendiente a demostrar que lo que se reclama a título de daño moral sea una afectación distinta a la simple molestia o perturbación propia de todo incumplimiento contractual. En tal sentido, conviene tener presente que la sola infracción de un contrato no da lugar a una reparación por daño moral porque la sola molestia, perturbación o desagrado que le genera al acreedor la transgresión no es suficiente para configurarlo como tal. De lo contrario, se llegaría al exceso de que todo incumplimiento en el marco mencionado generaría un daño moral, dado que esas consecuencias son propias a toda conculcación (Vergara Cubillos Rodrigo con Latam Airlines Group S.A., 2015, cons. 6)

Puede observarse la misma idea en la sentencias de la Corte de Apelaciones de Santiago del 23 de enero de 2015. (Andrés Ignacio Cifuentes Tarraza con Automotriz Rosselot S.A, 2015, cons. 3) y del 19 de febrero de 2015 (Juan Matías Silva Gaete con Central Parking System Chile S.A, 2015, cons. 3). Véase además, el voto disidente de la abogada integrante Carmen Domínguez ( $R o l$ No 1229-2011, cons 2.) y en el mismo sentido, el voto de minoría de la ministra Rutherford en Corte de Apelaciones de Santiago. 30 de enero de 2015. (Franco Furlanetto Pla y otro con Inversiones y Tarjetas S. A, 2015, cons. 3). 
En nuestra opinión lo que aquí sucede es que los tribunales, sirviéndose formalmente de la falta de prueba, descartan lo que hemos denominado "conexión automática" entre el incumplimiento contractual y la procedencia del daño moral. Algo que, por lo demás, es completamente pacífico en la doctrina (Domínguez Hidalgo, 2000, p. 305; Vidal Olivares, 2012, p. 649).

Nuestro segundo comentario se refiere, también, al interés patrimonial afectado. Como se recordará, la sentencia de la Corte de Apelaciones de Valdivia de 2 de octubre de 2001(Sociedad Agrícola y Forestal Casa Blanca Ltda. con Banco Santander Chile , 2001, cons. 1) se refiere a un interés extrapatrimonial, el honor. Sin embargo, entiende que, en virtud de lo dispuesto en el artículo 2331 del Código Civil, dicho interés no se encontraría protegido.

Nuestro tercer comentario se refiere también al honor, pero desde un ángulo distinto. Como ya se ha visto, la sentencia de la Corte de Apelaciones de Valparaíso de 11 de junio de 2014 (Carlos González Escobar con Corpbanca, 2014, cons. 10) niega lugar a la indemnización del daño moral por un protesto incorrecto publicado en Dicom, asumiendo, entonces, que el hecho de la publicación no basta para acreditar la lesión al honor.

\subsection{La cuestión de la previsibilidad}

Una cuestión es que haya un interés extrapatrimonial afectado que cuente como daño moral. Otra es que ese interés extrapatrimonial se encuentre protegido por el contrato o, como sugiere Barros Bourie (2006, p. 343), que su afectación sea previsible.

Encontramos una sentencia en que la Corte de Apelaciones de Santiago de fecha 18 de junio de 2009 (Testar y compañía Limitada /BBVA banco BHIF, 2009), también confirmada por la Corte Suprema (Testar y Compañía Limitada c. BBVA Banco $B H I F, 2011$, cons. 6), la cual, al ratificar la sentencia de primera instancia y hacer suyos los argumentos vertidos en ella, estima que la publicación en Dicom y en Boletín comercial no son daños morales indemnizables, toda vez que no son previsibles bajo la norma del 1558 del Código Civil. En la sentencia del tribunal de instancia se lee lo siguiente:

NOVENO: que en cuanto al daño moral, con todo lo que la doctrina ha discutido su procedencia en el ámbito contractual, cabe hacer presente que siendo las relaciones contractuales de orden patrimonial y por tanto las partes al celebrar un contrato deben precaver la forma de abordar las consecuencias que generaría el incumplimiento del contrato por cualquiera de las partes, no procede el daño moral en esta materia por no tener una naturaleza patrimonial, así se desprende del Art. 1558 del Código Civil, cuando señala 'si no se puede imputar dolo al deudor, sólo es responsable de los perjuicios que se previeron o pudieron preverse al tiempo del contrato' es por ello que 
en estos casos se demandan los daños emergentes y el lucro cesante, incluso se puede estipular una clausula penal, con el objetivo de resarcir los perjuicios que pudiere ocasionar el incumplimiento del contrato. (Testart y Cia./BBVA Bco. BHIF, 2006, cons. 9)

La idea de previsibilidad, tal y como lo entiende el tribunal de instancia - y lo confirma la Corte de Apelaciones de Santiago - se conecta con los intereses que protege el contrato. $Y$ la pregunta ha de ser si se limita a intereses patrimoniales o, en cambio, incorpora intereses de carácter extrapatrimonial. Una idea que, por lo demás, posee un vigoroso correlato en la doctrina (Barros Bourie, 2006, p. 343; De la Maza Gazmuri, 2016, pp. 570-574).

De esta manera, una sentencia como esta tendría cierta semejanza con aqueIla que descarta la tutela del honor en virtud del artículo 2331 del Código Civil. En ese caso sería la ley lo que limita la protección que dispensa el contrato respecto del honor de las partes. En cambio, en esta sentencia sería la previsibilidad lo que determinaría que, en ese caso, el honor del cuentacorrentista no estuviera protegido por el contrato.

\section{Las sentencias que acogen la indemnización del daño moral}

Como señalamos anteriormente, el total de sentencias que conceden daño moral por incumplimiento del contrato de cuenta corriente corresponde a 20. Dentro de ellas hemos distinguido un primer grupo en el cual no existen argumentos acerca de por qué se concede la indemnización por daño moral. Un segundo grupo, aun cuando no identifica el interés extrapatrimonial considera el incumplimiento del banco como doloso o con culpa grave. En fin, el tercer grupo identifica un interés extrapatrimonial. Dentro de esos intereses, encontramos seguridad, libertad y, predominantemente, honor.

\subsection{Sentencias que conceden la indemnización por el mero in- cumplimiento}

La sentencia de la Corte Suprema de 21 de octubre de 2010 (Meriño Figueroa, Marcos Atilio con Banco Santander Santiago, 2010, cons. 3) decide un caso en el que se había cobrado un mutuo inexistente, toda vez que efectivamente hubo tratativas para a llegar a un mutuo, pero no llegaron a contratar. Sin embargo, se descuenta la primera cuota en la cuenta corriente, además de enviarle avisos de vencimiento de la segunda cuota.

Sobre el daño moral que el incumplimiento le ocasionó, la sentencia señala que dicho incumplimiento contractual: "...le ocasiono a éste sin duda, aflicción, amargura, ansia y preocupación, razón por la cual el daño moral demandado debe ser acogido ..." (Meriño Figueroa, Marcos Atilio con Banco Santander Santiago, 2010, cons. 6). 
Se concede indemnización a título de daño moral por $\$ 1.000 .000$.

La segunda sentencia, de fecha 01 de julio de 2013 corresponde a la Corte de Apelaciones de Temuco (Mabel Cruz Muñoz con Banco Santander Chile, 2013, cons. 4 al 7). El cuentacorrentista demanda daño moral, toda vez que solicitó el cierre de la cuenta corriente al Banco, cosa que no ocurrió, además, le siguieron cobrando por la mantención de la tarjeta.

Señala, en lo que aquí interesa:

Que, por su parte, la doctrina ha señalado que el daño patrimonial es el que afecta al patrimonio y que el daño moral es todo menoscabo o detrimento no patrimonial que afecta la integridad psíquica del individuo, como la alteración en la tranquilidad de espíritu, molestias personales, inversión de tiempo en la solución de un problema, no cumpliendo de expectativas ofrecidas, impotencia, frustración o enojo a causa de un mal servicio. (Mabel Cruz Muñoz con Banco Santander Chile, 2013, cons. 11)

La Corte condena a la indemnización de $\$ 500.000$ por daño moral.

La tercera sentencia, de la Corte de Apelaciones de Temuco de 17 de julio de 2013. Se solicita la indemnización de daño moral producto de la clonación de la tarjeta de crédito del cuentacorrentista. Con relación al daño moral, la Corte señala lo siguiente:

Que si bien en el presente caso los hechos no dan cuenta de situaciones tan evidentes desde el punto de vista de la generación de un daño de carácter moral, las molestias padecidas por el cliente del banco y demandante en esta causa no pueden ser obviadas si se considera que tales molestias han derivado de una infracción cometida por el banco Santander a la legislación que protege los derechos de los consumidores. (Rol N94-2013, cons. 6)

Se concedió el daño moral por un total de $\$ 400.000$.

La cuarta sentencia también de la Corte de Apelaciones de Temuco de 19 de junio de 2013, donde, producto de una estafa informática realizada en el extranjero, a una persona se le extrajo dinero que se encontraba en su cuenta. El Banco, dos días después, devolvió la totalidad del dinero. Sobre el daño moral la Corte reflexiona:

Que la demanda civil deducida en los autos mediante la cual se impetra el pago de una indemnización por el daño moral sufrido por la actora, se sustenta en el perjuicio y sufrimiento que a ésta le significó la angustia y vergüenza pública a que se vio expuesta dañándose seriamente su derecho a la honra y derechos de propiedad debido a encontrarse en situaciones límites de su capacidad nerviosa, además de tener que vivir con esta angustia al desconocer qué ocurriría con su dinero y que tenía depositado en la seguridad del banco, el hecho de haber tenido que bloquear dos tarjetas, siendo una de ellas recién obtenida del banco, perder horas de trabajo y tiempo en 
trámites que se tradujeron en molestias físicas como irritabilidad, sin tener colaboración del banco Estado. (Rol N 73-2013, cons. 6)

Se condena al banco a indemnizar por concepto de daño moral $\$ 400.000$.

La quinta sentencia también es de la Corte de Apelaciones de Temuco de 30 de julio de 2013 (Gloria Cofian Huenchulaf con Banco Estado Chile, 2013, cons. 3), y se basa en los mismos hechos que la sentencia anterior, solo que producto de la estafa informática realizada, en este caso se le extrajo todo el dinero que se encontraba en su cuenta. El Banco, dos días después, devolvió la totalidad del dinero. Con relación al daño moral, la Corte de Apelaciones de Temuco señala lo siguiente.

SÉPTIMO: Que, a fin de acreditar el daño extrapatrimonial demandado, la actora se valió de los dichos de tres testigos quienes, en síntesis, expresan que ésta cuando les relato lo sucedido se encontraba tensa, muy afectada, temerosa, y que cuando acudió al Banco se encontró con mucha gente que había enfrentado la misma situación, teniendo que sufrir esperas, debiendo pedir permisos los días posteriores para aclarar el asunto, y seguía irritada y preocupada porque no podría pagar sus deudas.

OCTAVO: Que estas declaraciones unidas a la documental aparejada por la parte demandante a fojas 1 y siguientes, agregada de fojas 6 a 20, así como la propia instrumental de la demandada que se lee a fojas 42 y que corre agregada de fojas 47 a 83, valoradas de conformidad con las normas de la sana crítica, vale decir, sin contradecir los principios de la lógica, las máximas de la experiencia ni los conocimientos científicamente afianzados, permiten tener por acreditada la responsabilidad contractual del banco demandado y el daño moral experimentado por la actora a raíz de la situación que la afectó, daño moral que a juicio de esta Corte se desprende del efecto dañoso que en lo espiritual le ha causado el actuar de la demandada, lo que justifica acceder a su pretensión por tal capítulo, por el monto que ser dirá.

NOVENO: Que para fijar el quantum del perjuicio extrapatrimonial que se ha dispuesto resarcir, debe tenerse en consideración que el banco prontamente (como ha quedado consignado en el motivo quinto del presente fallo), reintegró a la actora las sumas fraudulentamente sustraídas desde su cuenta corriente, así como también el monto de las comisiones que cobró por los giros realizados desde el extranjero. (Gloria Cofian Huenchulaf con Banco Estado Chile, 2013, cons. 7, 8 y 9)

Y concede una indemnización por daño moral de $\$ 500.000$.

La sexta sentencia es de la Corte de Apelaciones de Temuco de fecha 19 de agosto de 2013 la cual también se basa en la estafa informática anteriormente descrita. Sobre el daño moral, debemos prestar atención a los considerandos octavo, noveno y décimo, los que señalan:

Octavo: Que, la demanda civil deducida en autos, mediante la que se impetra el pago de una indemnización por el daño moral sufrido por el actor, se 
sustenta en el perjuicio y sufrimiento que a éste le significó verse privado por algunos días de sus ingresos, con las naturales consecuencias que ello conlleva, perjuicio que en su concepto deriva única y exclusivamente de la conducta del banco demandado, el que, pudiendo implementar mejores sistemas de seguridad, no lo hizo.

Noveno: Que, si bien en el presente caso los hechos no dan cuenta de situaciones tan evidentes desde el punto de vista de la generación de un daño de carácter moral, las molestias padecidas por el cliente del bando y demandante en esta causa no pueden ser obviadas si se considera que tales molestias han derivado de una infracción cometida por el Banco del Estado a la legislación que protege los derechos de los consumidores.

Décimo: Que, para fijar el quantum del perjuicio extrapatrimonial que debe ser resarcido por la demandada, debe tenerse en consideración que éste prontamente reintegró al actor las sumas fraudulentamente sustraídas desde su cuenta $R$., como se consigna en el fundamento séptimo de esta sentencia. De esta manera, los pesares y desvelos del actor no se extendieron por más de dos días, por lo que esta Corte estima excesiva la cantidad fijada por el a quo por este concepto, razón por la cual se la rebajará en el monto que se precisará en lo resolutorio de este fallo. (Sebastián Soto Contreras con Banco del Estado, 2013, cons. 8,9 y 10 )

Se condena al Banco a indemnizar por un total de $\$ 240.000$ por daño moral.

La séptima sentencia, dictada por la Corte de Apelaciones de Antofagasta con fecha 26 de marzo de 2015, en donde se le atribuye como incumplimiento del contrato de cuenta corriente al Banco, el que haya entregado documentos relacionados a la utilización de la cuenta corriente a terceros, que no tenían mandato para la recepción de los documentos. Además, después de dicha entrega, todas las firmas que se utilizaron eran falsas, llegando a la persecución de los responsables en un proceso penal.

Para la sentencia existe daño moral pues la demandante:

... presenta un trastorno depresivo mayor, recidivante, en lo que respecta al daño moral, el representando, como, la afección psíquica que padece una persona a consecuencia de haber sufrido un conflicto o supera un desafío no común que genera angustia o dolor, obviamente frente a una persona normal la celebración de un contrato cuenta corriente, con línea de crédito, tarjeta de crédito, uso de cajeros automáticos y de medios financiero electrónicos, la falsificación de su firma en la apertura de uno de los contratos, y en la recepción de los productos asociados a una cuenta corriente que permitió la transferencia a un tercero de parte de los dineros depositados a esa cuenta, constituye en sí un daño moral que por tratarse de un hecho normal, debe presumirse y requiere de prueba en contrario para desvirtuarlo... (Víctor Hugo Rivera Castro con Banco Santander Chile, 2015, cons. 14) 

$\$ 2.000 .000$.

El monto que se ordena indemnizar por concepto de daño moral es

Probablemente, exista una diferencia relevante entre las primeras tres sentencias, por una parte, y la cuarta, quinta, sexta y séptima por otra. En las últimas existe una intervención de terceros con connotaciones penales, no así en las tres primeras.

Sin embargo, hemos decidido agruparlas porque, en nuestra opinión, se trata de casos en los que los tribunales únicamente se refieren a las molestias (la aflicción, amargura, ansia, preocupación, molestias personales, alteración en la tranquilidad de espíritu, etc.) que padecen los demandantes, pero en los términos en que las expresan parecen ser las molestias propias del incumplimiento de cualquier contrato y, por lo mismo, como ha sugerido Domínguez Hidalgo (2000) nos llevan a una "verdadera fantasía contractual" (p. 355) consistente en considerar que el mero incumplimiento del contrato origina una indemnización por daño moral.

Con esto no sugerimos que en estos casos no pueda haber un interés extrapatrimonial afectado como los que veremos a continuación; lo que afirmamos es que no se encuentra mención a él en el razonamiento de los respectivos tribunales.

\subsection{Sentencias que, de alguna manera, consideran un interés extrapatri- monial lesionado que el contrato protege}

Este es el grupo más voluminoso de sentencias. Al examinar aquellas decisiones judiciales que quedan comprendidas en él, el mínimo común denominador de todas ellas es la presencia de una lesión diversa -y más grave- que las molestias que, con toda probabilidad, causa cualquier incumplimiento contractual.

Por supuesto, no todas lo hacen con la misma elocuencia. En algunos casos los indican expresamente $y$, en otros, más bien debe extraerse esta conclusión de ciertas consideraciones de la sentencia.

Para sistematizar estas sentencias utilizaremos los intereses extrapatrimoniales a que, en nuestra opinión, ellas aluden. De esta manera, distinguimos entre la seguridad, la libertad y la honra.

\subsubsection{La seguridad}

La primera sentencia de seguridad es de la Corte de Apelaciones de Antofagasta, con fecha 2 de enero de 2015. La situación ocurrida es que se realizó una transferencia electrónica que no fue realizada ni autorizada por el dueño de la cuenta.

Con relación la seguridad, debemos prestar atención a los siguientes considerandos: 
Tercero: Que no se puede soslayar en un caso como éste, que los bancos desempeñan un papel fundamental en la actividad económica de un país, y que este papel descansa en gran medida en la imagen de seguridad, credibilidad y formalidad que proyectan al público y sus clientes, por lo que el nivel de exigencia para los bancos debe ser de una magnitud alta en comparación a un ciudadano medio, incluso para empresarios de otra índole.

Cuarto: Que en el caso de autos y de la prueba documental apreciada de conformidad a las reglas de la sana crítica, consistente de la instrumental que rola a fojas 1 a 7 , esto es, denuncias efectuadas a la Fiscalía local, a la Superintendencia de Bancos e Instituciones Financieras, de la respuesta dada por el Banco denunciado a una carta enviada por el demandante y de los documentos que rolan de fojas 29 a 80, consistentes en la investigación efectuada en sede penal, todos documentos que dan cuenta de una situación de transferencia electrónica, por parte de un tercero no conocido de la parte denunciante y no autorizada por el cliente del Banco ITAU (recurrente en esta instancia), por lo tanto, no existiendo prueba alguna de la demandada que desacredite los dichos de la demandante, se puede presumir que resulta evidente el incumplimiento de la obligación de seguridad del banco demandado...

Noveno Que es un hecho que la actora con motivo de los hechos denunciados obviamente sufrió desasosiego, molestias, y pérdida de tiempo, no logrando su solución directamente con la denunciada, obligando a aquella a formular denuncias sin resultado, para en definitiva, accionar y obtener judicialmente una sentencia favorable de indemnización por este tribunal de alzada fijando por concepto a título de daño moral en la suma de $\$ 800.000$ (ochocientos mil pesos, pedida por la recurrente... (Cristhian Carmona Carvajal con Banco Itau, 2015, cons. 3, 4 y 9)

El banco quedó obligado a pagar $\$ 800.000$ por daño moral.

Una segunda sentencia Corte de Apelaciones de Concepción de 26 de junio de 2015 (Oscar Mahuzier García con Corpbanca, 2015, cons. 1), conoce del caso de un cuentacorrentista que ingresa a la página de su banco, sin advertir que, en verdad, había ingresado a una página administrada por terceros, los que sustrajeron su número de cuenta y su clave secreta. Con los datos personales de la cuenta, los terceros sustraen la totalidad del dinero de la cuenta.

Por lo que toca a la seguridad, los siguientes considerandos nos parecen valiosos:

$\left.5^{\circ}\right)$ Que, en términos generales la doctrina opina que siendo el contrato un medio destinado a la circulación y comercialización de bienes y servicios, su incumplimiento sólo afecta los intereses patrimoniales o económicos comprometidos en la respectiva negociación; siendo así, las consecuencias extra patrimoniales derivadas de la contravención y que afecten al contratante di- 
ligente, no son indemnizables al exceder el ámbito de los intereses cautelados por el contrato y los riesgos asumidos por el deudor al contratar.

Sin embargo, algunos autores estiman que 'por excepción, hay ciertos contratos cuyo incumplimiento o cumplimiento imperfecto puede acarrear daños morales al acreedor. Esto ocurre en aquellos que imponen la obligación de seguridad personal a uno de los contratantes...' (Ver José Pablo Vergara Bezanilla, 'Comentarios sobre el daño moral en materia contractual', en Revista de Derecho del Consejo de Defensa del Estado N²6, año 2011, páginas 11 a 26).

$\left.6^{\circ}\right)$ Que, siguiendo al autor citado, conforme a la normativa de la Superintendencia de Bancos e Instituciones Financieras y de acuerdo a lo dispuesto en el artículo 1444 del Código Civil, el contrato de cuenta corriente suscrito entre el actor y el banco demandado, imponía al ente financiero la obligación de seguridad personal en favor de Oscar Mahuzier García; es decir, el banco Corpbanca debía garantizar al titular que las operaciones y transacciones que éste podía realizar en forma electrónica al acceder a la página web de dicha institución financiera, mediante la digitación de su número de rol único tributario y su clave secreta, eran seguras y que ningún daño ni perjuicio patrimonial le traerían consigo.

De acuerdo al artículo 1546 del mismo código, esta obligación que emanaba de la naturaleza del contrato suscrito entre las partes debía cumplirse de buena fe por ambos contratantes.

[...]10 $0^{\circ}$ Que, la reparación del daño moral debe comprender el justo resarcimiento del perjuicio extrapatrimonial o inmaterial sufrido por el contratante diligente, derivado del incumplimiento del deudor. Es evidente que el perjuicio señalado lo sufrió el actor al haberse visto privado de un momento a otro de la totalidad de sus haberes depositados en la cuenta corriente $N^{\circ} 62$ 401680, de la cual éste era su titular ante el banco Corpbanca... (Oscar Mahuzier García con Corpbanca, 2015, cons. 5, 6 y 10)

Se condenó al banco al pago de $\$ 3.000 .000$ por daño moral.

\subsubsection{La libertad}

Por lo que toca a la libertad, a diferencia de lo que sucedía tratándose de la seguridad, las dos sentencias que consideramos no se refieren explícitamente a ella como interés extrapatrimonial protegido por el contrato, sin embargo, sí que se refieren, a propósito del daño moral, a que los demandantes estuvieron privados de libertad. En ellos, debido al incumplimiento del Banco, los dueños de la cuenta corriente terminaron detenidos. 
En el primer caso, de la Corte de Apelaciones de Santiago de fecha 4 de noviembre de 2005, confirmada por la Corte Suprema ${ }^{4}$, el Banco realizo un protesto por orden de no pago. El cheque había sido anteriormente rechazado por caducidad en dos oportunidades anteriores. Debido a este protesto, es que el demandante estuvo en prisión durante alrededor de 18 horas.

Los considerandos que nos interesan los siguientes:

TERCERO: Que a la época en que fue privado de libertad el demandante, era accionista de una importante óptica y el hecho de estar detenido una tarde, una noche y toda una mañana le significó un perjuicio grande ya que nunca antes se había visto en tales situaciones, al decir del atestado que rola a fs. 36 de autos, corroborado en lo fundamental por la declaración testimonial de fs. 37 del expediente.

CUARTO: Que, a juicio de los sentenciadores, es plenamente procedente el daño moral materia de responsabilidad contractual según lo reconoce tanto la jurisprudencia como la doctrina al interpretar los alcances del Art. $1556 \mathrm{del}$ Código Civil. En efecto, entre otros fallos, es dable considerar: Excma. Corte Suprema, sentencia 3 de septiembre 2002 Rol $N^{\circ} 4035-01$ y sentencia 5 de noviembre 2001, Rol 1368-00; y en la Doctrina tanto nacional como extranjera, la opinión de distintos tratadistas.

QUINTO: Que se encuentra acreditado en la especie, por los medios legales, el daño moral sufrido por el demandante como consecuencia de actos que son plenamente atribuibles a la demandada, por lo que es pertinente que repare los perjuicios que los mismos han provocado. (Manuel Valente Docasar con Banco Citibank, 2008, cons. 3, 4 y 5)

La indemnización por daño moral ascendió a \$5.000.000.

El segundo caso corresponde a la Corte de Apelaciones de Concepción, de fecha 6 de enero de 2009. Al protestar un cheque, el banco estableció en el acta de protesto un domicilio distinto al registrado del demandante. Debido a ello, no consignó fondos al tercer día, lo que llevo a ser acusado de giro doloso de cheques, dictándose orden de arresto en su contra, la cual lo llevo a permanecer un par horas en la comisaria.

Nos interesa el siguiente considerando:

$13^{\circ}$ Que en orden a acreditar el daño moral que reclama obra en autos, acompañó copia autorizada de la causa Rol N. ${ }^{\circ} 39.123$ del Segundo Juzgado del Crimen de Talcahuano, en la que consta que el demandante fue detenido el 22 de noviembre de 2002 por la Policía de Investigaciones, por registrar orden de aprehensión pendiente por el delito de giro doloso de cheque en la causa Rol N. ${ }^{\circ}$ 39.123, permaneciendo detenido hasta el día 23 de noviembre,

\footnotetext{
${ }^{4}$ Con todo, nada dice sobre el daño moral concedido. 
fecha en que fue puesto en libertad por haber rendido fianza. (Erick Daniel UIriksen Schmidlin con Banco de Crédito e Inversiones BCI, 2009, cons. 13)

Se condena a indemnizar daño moral por un total de $\$ 8.000 .000$.

\subsubsection{La honra}

Las sentencias que se refieren a la honra configuran el grupo más voluminoso. Para presentarlo distinguiremos según si el incumplimiento del banco determinó o no una publicación en algún registro comercial.

A) El incumplimiento determina la publicación en un registro comercial

La primera sentencia, de la Corte de Apelaciones de Valparaíso de 6 de junio de 2005, confirmada por la Corte Suprema (Enrique Le Dantec Gallardo con Banco de Chile, 2007, cons. 8) ${ }^{5}$, conoce de un caso de cierre injustificado de cuenta corriente, con el consecuente no pago protesto de cheques y publicación en Dicom. La Corte de Apelaciones estima que: "... la circunstancia de que los referidos documentos mercantiles hayan sido protestados con la consecuente publicidad de tal hecho, causó perjuicios al demandante, por una conducta negligente de la institución bancaria demandada, por lo que, a juicio de esta Corte, dichos daños deben ser indemnizados" (Le Dantec Gallardo Enrique con Banco de Chile, 2005, p. 4).

Fija como indemnización del daño moral $\$ 30.000 .000$.

La segunda sentencia, de fecha 19 de julio de 2005, corresponde a la Corte de Apelaciones de Concepción. Estando vigente y con fondos la cuenta corriente, el banco protestó un cheque. Dicho incumplimiento contractual determinó el siguiente pronunciamiento de la Corte:

30. Que el daño moral sufrido por el demandado, se origina por la relación de causalidad existente en el incumplimiento del banco de no pagar los cheques, por haber sido protestados, existiendo fondos para cancelarlos y estar vigente la cuenta corriente y línea de crédito, este solo hecho, el protesto de los documentos, añadido a su calidad de comerciante, le causó molestias que trascendieron a un daño moral probado con los testimonios de Luis Molina Villagrán, Moisés Fierro Jara y Pedro Lagos Roa. El primero manifiesta que el actor sufrió una enfermedad psicológica, y que está en el boletín comercial el otro, que 'se vela bastante amargado' y que no puede girar cheque porque está en Dicom y el tercero, que el demandante estuvo con tratamiento médico por depresión. (Juan Bautista Bustos Ortega con Banco Santander Santiago, 2005, cons. 3 )

En el considerando $5^{\circ}$ se agrega lo que sigue:

\footnotetext{
${ }^{5}$ No se añade en ella nada relevante respecto del daño moral. 
$5^{\circ}$. Que todo ello está directamente concatenado, con el daño moral sufrido por el demandante en los términos dados por probados en el fundamento tercero, daño moral que sin duda tuvo que repercutir psíquicamente en el entorpecimiento de sus actividades comerciales generando los perjuicios psicológicos o morales ya expresados... (Juan Bautista Bustos Ortega con Banco Santander Santiago, 2005, cons. 5)

El quantum del daño se establece en $\$ 5.000 .000$.

Una tercera sentencia de la Corte de Apelaciones de Concepción, esta vez de 3 de noviembre de 2005, confirmada por la Corte Suprema (Juan Luis Arellano Vaillant con Banco Santiago, 2007, cons. 9) ${ }^{6}$, condena al banco debido a qué informó al Boletín Comercial un monto mayor al adeudado verdaderamente por el demandante. Para conceder el daño moral, razona sobre la procedencia del daño moral de la siguiente manera:

Precisada la procedencia del daño moral en materia contractual, es necesario precisar que es carga de quien lo reclama probar su existencia, toda vez que no toda infracción de un contrato produce necesariamente un daño moral.

En ese orden de cosas, la única prueba rendida por la parte demandante es la prueba testimonial cuya acta se agregó de fs. 107 y siguientes y referida en el motivo 12 de la sentencia que se analiza. (Juan Luis Arellano Vaillant con Banco Santiago, 2005, cons. 15)

Se condena al banco a pagar por concepto de daño moral $\$ 3.000 .000$.

La cuarta sentencia de este grupo dictada por la Corte Suprema, de 14 de octubre de 2008. El incumplimiento del banco consistió en publicar en el Boletín de forma errónea la deuda de dos cuotas de un mutuo hipotecario, que habían sido ya pagadas por el demandante. La Corte estima infringido el artículo 1546 del Código Civil, y el artículo 16 de la ley 19.628, sobre la protección de datos personales. Considera: "Que el demandado sufrió un detrimento o menoscabo psicológico que deviene necesariamente de la publicación en el boletín comercial de una calidad de deudor inexistente;" (Luis Gonzaga García Ortiz con Scotiabank, 2008).

Condena al banco a indemnizar el monto de $\$ 5.000 .000$ en virtud del daño moral.

En quinto lugar, encontramos una sentencia de la Corte Suprema de 31 de enero de 2011. El incumplimiento, esta vez, consiste en no cargar a la cuenta corriente una cuota de un mutuo hipotecario. En vez de cobrarlo, el banco envía los antecedentes a Dicom. En el considerando cuarto se lee lo siguiente: "... se encuentran justificadas las consecuencias del perjuicio no patrimonial [...] por haberse afectado su dere-

\footnotetext{
${ }^{6}$ Nada hay en ella, sin embargo, de interés para el daño moral.
} 
cho a la honra mediante la inclusión en los registros públicos de deudores morosos" (Campos Contreras, Mauricio Eugenio c. Banco Santander Chile, 2009).

Se condena al banco al pago de $\$ 5.000 .000$ por indemnización de daño moral.

La sexta sentencia, también de la Corte Suprema, de 4 de julio de 2011, conoce del caso de un envío a Dicom de los datos de una deuda que se encontraba prescrita, y que, además, nunca ejerció acciones de cobro, como nunca tampoco cargó el monto de la deuda a la cuenta corriente, facultad que también poseía.

En sus considerandos 16 y 17 leemos lo siguiente:

... por consiguiente, asignar valor de plena prueba a las circunstancias narradas por ellos, en cuanto a la afectación psíquica o anímica ocasionada al demandante, consistente en los sentimientos de vergüenza, turbación e incomodidad por los inconvenientes experimentados por éste y presenciados por los deponentes, como al tratar de pagar con cheques diversas cuentas por compras de bienes y servicios, los que eran rechazados por aparecer registrado en el boletín comercial; circunstancia que, además, al decir del testigo del señor Aguirre Vadillo, le significo al demandante haber llegado a sostener varias entrevistas de trabajo, las que no rindieron frutos, precisamente por mantener el citado registro.

Además, por el cariz cotidiano que denotan aquellos episodios descritos por los testigos, los mismos son posibles extrapolar a los distintos ámbitos del desenvolvimiento de la vida cotidiana de un sujeto adulto, dejando entrever que tales escenas en que distintos operadores, fundamentalmente, del comercio rechazaban pagos con cheques al actor, por figurar registrado como deudor moroso [...]

$\left.17^{\circ}\right)$ Que es sabido es que la ley no entrega parámetros expresos para determinar el daño moral, entendido como el sufrimiento, dolor o aflicción espiritual, moral y afectiva que ha debido sufrir el actor [...]

[...] los sentimientos de vergüenza preocupación y amargura, comprometidos en las dificultades para interactuar en establecimientos se comercial en quehaceres habituales de la vida diaria y el desmedro de sus posibilidades a la hora de postular a nuevas fuentes de trabajo, para las que resultó de relevancia que el actor presentara una deuda vencida... (Julio Fritz Vidal con Banco Santander Chile, 2011, cons. 16 y 17)

Se condenó al Banco a pagar $\$ 5.000 .000$ por concepto de daño moral.

En séptimo lugar tenemos una sentencia del $13^{\circ}$ Juzgado Civil de Santiago (Hidalgo / Banco de Credito e Inversiones 2012, cons. 15), de fecha 9 de agosto de 2012, confirmada por la Corte Suprema (H.R.P.L. con Banco de Crédito e Inversiones, 2014), en donde el incumplimiento consiste en la entrega de 32 chequeras a un tercero en virtud de un mandato falso, en donde se protestaron dichos cheques, enviado a la demandada a los registros de Dicom. Respecto al daño moral, estima que: 
...le ocasionó a la actora un grave dolor o aflicción relativo a sus sentimientos y que le trajo consecuencias tanto familiares como laborales, y teniendo presente que el daño moral se caracteriza por atentar contra los derechos de la personalidad, lo que significa que él consiste en la lesión o detrimento que experimenta una persona en su honor, su reputación, su integridad física o sicológica, su libertad, sus afectos, estabilidad y unidad familiar, esto es, en general, los atributos o cualidades morales, con las consiguientes repercusiones en la normalidad de su existencia, cabe concluir que en la especie concurre el daño alegado por al [sic] actora. (Hidalgo / Banco de Credito e Inversiones, 2012, cons. 17)

Se condena a indemnizar $\$ 3.000 .000$ por concepto de daño moral.

La octava sentencia, de la Corte Suprema de 30 de marzo de 2012 (Olivi Melendez con Banco Santander Chile, 2012, cons. 3), conoce un caso en el que se manifiestan una serie de incumplimientos del banco. Ante todo, el demandante realiza un prepago que corresponde a un crédito hipotecario que tenía con el Banco. Sin embargo, de igual forma se le cobra dos cargos a la cuenta, a título de dividendos, siendo que se encontraba íntegramente pagado. Debido a los cargos, se incurrió en sobregiro, lo que llevo a que se haya protestado un cheque. Además, envió a Dicom los antecedentes debido al crédito hipotecario ya pagado. El considerando que nos interesa es el siguiente:

DUODECIMO: Que entendido el daño moral como el sufrimiento, trastorno sicológico, afección espiritual o lesión de un interés personalísimo, causado a la espiritualidad de la víctima como consecuencia de la comisión de un hecho ilícito o de la infracción a un derecho subjetivo, no definible por parámetros objetivos, que puede afectar a la víctima o a un tercero, pudiendo consistir en un daño moral puro o bien de índole pecuniario cuando indirectamente afecta la capacidad productiva del perjudicado, corresponde dilucidar si el incumplimiento atribuido a la entidad bancaria demandada ha importado un menoscabo de tipo moral al actor, resultando palmario que las conductas desplegadas por el banco, como el envío de sus antecedentes como deudor moroso a Dicom- sin serlo-, el protesto de un cheque indebidamente realizado por el banco, el cargo de dividendos inexistentes y los demás abusos denunciados por el actor indudablemente le provocaron angustia, impotencia y descrédito, como se dio por acreditado, perjuicios que naturalmente le deben ser resarcidos por el contratante que quebrantó las obligaciones que en virtud de la convención celebrada debió respetar, razón por la cual la decisión indemnizatoria adoptada por los jueces del grado se ajusta al mérito de lo prevenido en el artículo 1556 del Código Civil. (Olivi Melendez con Banco Santander Chile, 2012, cons. 12)

Se condena a pagar el monto de $\$ 20.000 .000$ por el daño moral sufrido por el demandante.

La novena sentencia es de la Corte de Apelaciones de Santiago de 3 de enero de 2013, confirmada por la Corte Suprema (H.M., M.E. con Scotiabank Chile, 2013) en 
donde se envió al Boletín comercial por el mal protesto de un cheque por cuenta cerrada. Respeto al daño, la Corte estima:

$\left.3^{\circ}\right)$ Que, en consecuencia, la publicación del protesto en un registro públi$c o$, en circunstancias que no era efectivo el incumplimiento de que daba noticia, teniendo presente el estado y condición particular del actor, naturalmente debió producirle sufrimiento y aflicción, amén de las consecuencias comerciales típicas que ocasiona la inclusión de una persona en los listados de deudores morosos, por lo que es posible presumir la existencia del daño moral que alega en cuanto la merma de su imagen y honra ha debido necesariamente afectarle. (Mauricio Hernández Muñoz con Scotiabank Chile, 2013, cons. 3)

Se conceden 3.000 .000 por concepto de daño moral.

En décimo lugar, encontramos una sentencia de la Corte de Apelaciones de Talca de 29 de septiembre de 2014, confirmada por la Corte Suprema -nada hay en ella respecto del daño moral- (Moisés Muñoz Concha con Banco Santander Chile, 2015). Una vez más, se trata de un envío incorrecto de los antecedentes del demandante a Dicom. En la sentencia leemos:

En lo que respecta al daño moral, la cantidad fijada por el tribunal de Primera Instancia de $\$ 12.000 .000$ parece condigna con las molestias sufridas, teniendo presente para ello que en su desempeño como Fiscal Judicial ha sido siempre muy bien calificado como funcionario de excelencia, lo que por lo demás es un hecho público y notorio y no ha sido tampoco afectado en su desempeño académico. (Muñoz Concha Moisés Olivero con Banco Santander Chile, 2014, cons.10)

Al considerar la justificación del monto en la sentencia de primera instancia, encontramos que:

...el actor sufrió vergüenza, stress psicológico, viendo afectado su honor e intimidad comercial, daño este de una envergadura que, conforme el mérito del proceso y de las pruebas referidas, y atendido el tiempo transcurrido desde que ocurrieron los hechos y por el que se ha prolongado, en consecuencia, este daño moral...(Muñoz / Banco Santander-Chile, 2013, cons. 19)

Se condena al banco a pagar la suma de $\$ 12.000 .000$.

La undécima sentencia es de la Corte de Apelaciones de Santiago de 28 de enero de 2014. En el caso, se solicita el cierre de la cuenta por parte del cuentacorrentista, con todo, el banco nunca realizó el cierre. Producto de dicha omisión, se realizaron cargos improcedentes a la cuenta. Sobre el daño moral, encontramos en el considerando segundo:

Que la acción deducida por el demandante se sustenta en los daños y perjuicios que le causó el demandado toda vez que, a pesar que cerró con fecha 
20 de junio del año 2003 la cuenta corriente que mantenía con la demandada Corpbanca, ésta lo informó como deudor a la Superintendencia de Bancos e Instituciones Financieras en el mes de Mayo del año 2004, lo que le produjo daño moral como consecuencia del desprestigio que se le causó al incluirlo en el boletín comercial y los registros históricos del sistema financiero sin que hubiere motivo plausible para ello. (Dagoberto Ramos Sanhueza con Banco Corpbanca, 2018, cons. 2)

Se condena al banco al pago de $\$ 4.000 .000$ por indemnización de daño moral.

La duodécima sentencia es de la Corte Suprema de 31 de agosto de 2016. El banco había aceptado una repactación a más largo plazo con menos comisión. Sin embargo, se le cargó a la cuenta corriente 3 cuotas del crédito anterior, sin tomar en consideración la nueva negociación. Es por esto, que el Banco cierra la cuenta y envía los antecedentes a Dicom. Con respecto al daño moral, la Corte estima lo siguiente:

...es indemnizable en la medida que sea una consecuencia inmediata y necesaria del incumplimiento del contrato, tal como ocurrió en la especie, mediante la conducta de la demandada en los términos antes descritos, y siempre que afecte intereses que vayan más allá de los resultados puramente patrimoniales y se refieran en cambio a la personalidad moral del individuo. (Víctor Mena Lobos con Banco Santander, 2016, cons. 11)

Se declara que se debe indemnizar $\$ 20.000 .000$ por concepto de daño moral.

Por último, la sentencia de la Corte de Apelaciones de Coyhaique de 18 de julio de 2017 (Fischer Valenzuela, Rodrigo con Banco de Crédito e Inversiones, 2017, cons. 9). El incumplimiento del banco consiste en enviar los antecedentes del cuentacorrentista por una deuda pagada. Sobre el daño moral se señala:

...fundado precisamente en que no se realizó los resguardos necesarios para que, con posterioridad a la solución de la deuda por tarjeta de crédito, se informara al boletín comercial de tal situación en la oportunidad debida, y tan solo se hizo casi un año después haciéndosele figurar en el Dicom por todo ese tiempo, lo que revela una inadecuada condición de seguridad, sin perjuicio de que además no se informó al usuario de tal hecho. (Fischer Valenzuela, Rodrigo con Banco de Crédito e Inversiones, 2017, cons. 7)

Se condena al banco indemnizar $\$ 600.000$ por concepto de daño moral.

B) Sentencias en que no existe publicación en un registro comercial

En primer lugar, encontramos una sentencia de la Corte Suprema de 25 de enero de 2011 (Sociedad Educacional Colegio Alemán de Arica Limitada y otra con Banco del Estado de Chile, 2011, cons. 2), que conoce de un caso en que la sostenedora de la sociedad educacional demandante, giro un cheque, con el cual se iban a pagar las cotizaciones previsionales de los y las trabajadoras de la sociedad educacional. Sin embargo, el Banco había protestado por firma disconforme, siendo que había sido 
firmado por la dueña de la cuenta, o su representante, y que existían fondos para realizarlo. Nos interesa el siguiente fragmento de la sentencia:

DECIMONOVENO: Que, junto con la noción de daños material es la doctrina y la jurisprudencia han incrementado la idea del daño moral, concepción que es vista con criterios más amplios, incluyéndose en ella incluso los efectos de las lesiones que un individuo experimenta en su integridad corporal, en su salud física y en su salud psíquica, criterio que también se ha ampliado a aquellas circunstancias que han afectado gravemente el prestigio comercial, el honor y otros ítem que implique de por si una afectación a la persona humana. En el caso de autos, donde el demandante doña Luz Marina Osorio Bahamondez, representante de la Sociedad Educacional de Arica Limitada se confunde en el rol funcional con la persona jurídica que representa, ya que su condición de sostenedora por parte de la institución educacional implica que dicha función se realice por el ente de enseñanza, pero siempre respaldado por la persona natural que la representa, debiendo en tal caso conjugarse ante la autoridad ministerial respectiva de educación una conducta intachable en el ámbito comercial y bancario, de tal forma que en el evento de haberse realizado, tal como acaeció en la especia, un protesto injustificado de un documento mercantil, obviamente, se ha producido un menoscabo que debe ser indemnizado tanto a la persona natural como a la persona jurídica del giro educacional. (Sociedad Educacional Colegio Alemán de Arica Limitada y otra con Banco del Estado de Chile, 2011, cons. 19)

La indemnización del daño moral se fijó en \$1.000.000 tanto como a la persona natural como al colegio demandante.

La segunda sentencia, de 12 de mayo de 2015, de la Corte de Apelaciones de Antofagasta (Dagoberto Zavala Jiménez con Banco de Crédito e Inversiones, 2015, cons. 4) resuelve un caso en que debido a un error de tipeo de un funcionario del banco se estimó que una cuenta corriente vigente y con fondos se encontraba cerrada, por lo mismo se protestó un cheque.

De todas las sentencias consideradas esta es, con diferencia, la que contiene un tratamiento más detallado de la cuestión del daño moral. Comienza con la siguiente definición de daño moral:

Respecto de la conceptualización del daño, es efectivo que hay diversas opiniones. Sin embargo, la más aceptada modernamente por la doctrina, es aquella que lo concibe como la lesión, menoscabo o detrimento a intereses extrapatrimoniales. La cuestión conceptual es importante en esta materia, por cuanto, para que se configure el perjuicio, de aquellos reclamados por el demandante, es indispensable que demuestren la lesión a un interés extrapatrimonial específico, no bastando la mera referencia a dolores o pesares, que no necesaria y directamente se traducen en menoscabos tutelados. (Dagoberto Zavala Jiménez con Banco de Crédito e Inversiones, 2015, cons. 11) 
Luego, avanza sobre las condiciones de procedencia de dicha partida indemnizatoria e indica que debe tratarse de un daño directo y previsible a la época de celebración del contrato. Por lo que toca, el interés extrapatrimonial, la sentencia nos indica:

Particularmente tratándose del honor, sabemos que éste tiene dos dimensiones: una objetiva y otra subjetiva. En relación con el aspecto objetivo, es decir, la reputación social y comercial de la víctima, esta Corte advierte, en el sentido de la valoración del daño que ha hecho el sentenciador, que efectivamente está acreditada la afectación de la reputación para con la Comunidad propietaria del cheque afectado por la conducta culposa del banco demandado, pero no se comparten todos los alcances que el actor pretende.

Ciertamente, contrariamente a lo sostenido por el actor, no se encuentra probado en autos el descrédito general que considera existió. En término, es un indicativo de importancia que el protesto no tuviese publicidad formal, ni comercial alguna. Precisamente, los hechos alegados como afectaciones comerciales, dan cuenta que antes al contrario, no tuvo alguna: la preocupación de cumplimiento por parte de los arrendatarios revela que la imagen comercial del señor Zavala permaneció intacta; de otro lado, los supuestos llamados telefónicos de otros ejecutivos para la apertura de cuenta corriente en otros bancos, amén de ser de regular ocurrencia, precisamente permiten concluir lo contrario, es decir, que no hubo descrédito en el sentido apuntado.

Todo indica que los razonamientos del demandante apuntan a una clara afectación de la esfera subjetiva del honor, es decir, la propia imagen que el actor tiene frente a la comunidad, pero en la medida que tal afectación incide en la esfera psíquica, por dicho concepto es procedente la reparación de los perjuicios $y$, en otros casos, no pueden atribuirse todas las consecuencias del hecho al banco demandado, porque no quedan comprendidas todas en la causalidad. (Dagoberto Zavala Jiménez con Banco de Crédito e Inversiones, 2015, cons. 12)

En lo que corresponde a la previsibilidad del daño, resulta necesario citar en extenso:

DÉCIMO TERCERO: En este sentido, procede, en principio, la aplicación del segundo criterio normativo contenido en el artículo 1558. La norma limita la indemnización a los daños efectivamente previstos en el contrato o a aquellos que se pudieron prever al tiempo del contrato. Como indica Corral, la previsibilidad aquí no juega el rol propio de la causalidad, porque el juez no debe colocarse en el momento del incumplimiento, sino en el momento de celebración del contrato. Al respecto, señala Corral: 'De todos los daños de los que se reconoce una causalidad, porque han sido previsibles en el momento en que el deudor infringió la obligación, sólo deberá indemnizar aquellos que eran previsibles cuando el contrato fue celebrado'. (CORRAL TALCIANI, Hernán, Contratos y daños por incumplimiento, Santiago, AbeledoPerrot, 2010, p. 177). En el fallo de la Corte Suprema, de 27 de octubre de 2010, rol 277809 (indicador Microjuris MJJ25491) se acogió el recurso de casación en el fondo 
respecto de la sentencia de segunda instancia que había pasado por alto la aplicación del artículo 1558. La Corte es bastante clara en destacar que cuando los daños reclamados no son resultado de la infracción, ni pueden preverse al tiempo del contrato, no se deben indemnizar. Dijo la Corte: 'Corresponde acoger el recurso de casación en el fondo interpuesto en contra de la sentencia, que acogió la demanda de resolución de contrato de licencia de marca ordenando el pago de los perjuicios por concepto de daño emergente, toda vez que yerran los jueces recurridos que ordenaron a la demandada (Iicenciante) a pagar a la actora (licenciatario), el precio pagado por compra de materias primas e insumos, adquiridos y tratados por una tercera empresa, por cuanto el rubro en mención, que según la demandante y el fallo impugnado sería un daño emergente indemnizable, no tiene realmente tal carácter, puesto que no son consecuencia inmediata y directa del incumplimiento de la demandada ni tampoco se previeron o pudieron preverse al momento del contrato. No son resultado de la infracción de la obligación. Se trata de perjuicios que no se hallan íntimamente ligados al incumplimiento de las obligaciones resultantes del contrato; no son la consecuencia lógica e inmediata de ese incumplimiento. Los jueces no han establecido que se pueda imputar dolo a la demandada y tampoco la demandante se lo ha atribuido. Acorde con ello cuando no se imputa dolo al deudor, según los términos del artículo 1558 , los perjuicios indemnizables tienen que ser, una consecuencia inmediata y directa del no cumplimiento del deudor y, además, de la clase de los que se previeron o pudieron preverse en el momento de contratar. Por lo expuesto, si se acoge la acción de perjuicios prescindiendo de elementos o antecedentes jurídicos esenciales e inherentes a tal acción, infringe la disposición legal que los exige'.

Para el caso del daño moral, la cuestión guarda completa relevancia, al punto que la doctrina entiende que, como regla general, el contrato con prestaciones patrimoniales no puede dar lugar a indemnización por daño moral, a menos que las partes pudiesen preverlo al tiempo de la celebración. En este sentido se han pronunciado Corral y Domínguez, por ejemplo. (CORRAL, cit., p. 198. DOMÍNGUEZ, El Daño Moral..., p. 546).

Que analizada desde la perspectiva del citado artículo 1558, los perjuicios alegados por el actor no podrían ser calificados de previsibles a la época de celebración, salvo aquellas lesiones al honor, que pueden ser asociadas a la mantención de una cuenta corriente.

DÉCIMO CUARTO: Que sin perjuicio de lo razonado precedentemente, las normas que regulan la reparación de daños en la Ley 19.496, sobre protección de los consumidores, plenamente aplicables en la especie, abonan la procedencia de la indemnización de perjuicios. En principio, porque el artículo 3, letra e) dispone que la víctima tiene derecho a la reparación e indemnización adecuada y oportuna de todos los daños materiales y morales en caso de incumplimiento (no de infracción) de cualquiera de las obligaciones contraídas por el proveedor. 
Que en cuanto al daño moral, entendido como la lesión de los intereses extrapatrimoniales de la víctima, debemos tener presente que no resulta automáticamente aplicable el artículo 1558 del Código civil, que en materia contractual limita los efectos de la reparación del daño a los perjuicios directos y previstos al tiempo de la celebración del contrato, toda vez que el artículo tercero de la Ley $N^{\circ} 19.496$ consagra siempre en favor de la valoración del daño,

Desde esta perspectiva, la morigeración de la previsibilidad del daño importa, a juicio de esta Corte, que la valoración que ha hecho el juez a quo ha sido ajustada a Derecho, en términos de las lesiones a la integridad psíquica y al honor subjetivo. (Dagoberto Zavala Jiménez con Banco de Crédito e Inversiones, 2015 , cons. 13 y 14 )

Se conduce en este caso la suma de $\$ 8.000 .000$ de indemnización de daño moral.

\subsubsection{Sentencias que consideran la gravedad del incumplimiento}

Dentro de las sentencias que conceden daño moral, existen dos en que se determinó que el Banco actuó con dolo o culpa grave. La primera de ellas corresponde a una de la Corte Suprema de fecha 3 de julio de 2007. En este caso el titular de la cuenta corriente sufrió un robo de su cédula y una tarjeta bancaria, dando noticia de ella al banco. No obstante, lo anterior, la tarjeta no se bloqueó lo que permitió a la ladrona solicitar un mutuo y girar dinero. La cuentacorrentista no pagó el mutuo ni las compras realizadas en la tienda, producto de lo cual no solo se le exigió el pago, sino que, al no hacerlo se le envió al Boletín comercial.

Estimó la Corte que existía un incumplimiento contractual por parte del banco, en los siguientes términos:

TRIGÉSIMO: Que, según se ha indicado con anterioridad, la demandada incurrió en responsabilidad derivada de la declaración de nulidad parcial de la cláusula décimo tercera del Reglamento de Uso de la Tarjeta de Crédito Multirrotativo CMR y de los cargos realizados el día 21 de diciembre de 2002 en la cuenta individual de Luisa Isabel Hermosilla Bonassi, puesto que su proceder ha quedado sin justificación contractual, el cual se ha realizado de manera voluntaria, con la expresa intención de producir un detrimento en la situación patrimonial de la demandante y, de este modo solventar el pago de las obligaciones que pretendía cobrar a la actora, de forma tal que concurre no sólo culpa grave o lata, en los términos del artículo 44 del Código Civil, sino que dolo, en atención al conocimiento integral que ha tenido de los hechos en sus diversas circunstancias, no obstante ha realizado las más variadas acciones destinadas a producir injuria en los bienes de Isabel Hermosilla Bonassi y no ha podido menos que representarse y aceptar las repercusiones en la persona de la demandante, especialmente en su salud y reputación comercial, como ha quedado demostrado en autos. 
Los hechos establecidos dejan claramente determinada la acción dolosa, los daños y la relación de causalidad, como la ausencia de justificación legal de la conducta de la demandada.

De esta forma la responsabilidad de la demandada se extenderá respecto de todos los perjuicios que fueren consecuencia inmediata o directa de su acción, conforme lo establece el artículo 1558 del Código Civil. (Luisa Isabel Hermosilla Bonassi con Promotora CMR Falabella S.A., 2007, cons. 13)

La Corte condenó al pago de $\$ 25.000 .000$ por concepto de daño moral.

El segundo caso corresponde a una sentencia de la Corte Suprema de 7 de septiembre de 2009. El banco realiza un cargo improcedente, a principio de mes, a la cuenta corriente por alrededor de $\$ 42.000 .000$. Producto de lo cual se quedó sin fondos para pagar un cheque que luego fue protestado por falta de fondos. El considerando que nos interesa es el siguiente:

En base a los hechos relacionados precedentemente los sentenciadores concluyeron que el banco demandado contravino la obligación principal que imponía el contrato, incumplimiento que debe atribuirse a culpa o negligencia grave, acorde con lo preceptuado en los artículos 44 y 1547 del Código Civil y la naturaleza del contrato, toda vez que los hechos señalados y su secuencia lógica revelan un descuido máximo en el manejo de la cuenta corriente del actor, por cuanto en dos oportunidades, 11 y 29 de febrero de 2000 se le efectuaron cargos indebidos e improcedentes los que fueron causa directa del protesto del cheque girado por el demandante a la orden del Banco Bhif, no obstante que disponía de los fondos necesarios para su pago. (Banco Santander contra, 2009, cons. 2)

La indemnización por daño moral que concede la Corte asciende a $\$ 20.000 .000$.

\section{Mero incumplimiento, intereses extrapatrimoniales y gravedad del incumplimiento}

Según nos parece, la revisión de las sentencias que conceden una indemnización por daño moral frente al incumplimiento por parte del banco del contrato de cuenta corriente, enseñan algunas cuestiones que pueden contribuir a la sistematización de esta partida indemnizatoria en esta especie de contratos.

En primer lugar, no obstante, la presencia de un par de sentencias que, aparentemente conceden indemnización por las simples molestias que, generalmente, causa un incumplimiento contractual (Ver, por ejemplo, Meriño Figueroa, Marcos Atilio con Banco Santander Santiago, 2010, cons. 7; Mabel Cruz Muñoz con Banco Santan$\operatorname{der}$ Chile, 2013, cons. 12), la tendencia parece ser que ese tipo de molestias no resulta suficiente para justificar la indemnización del daño moral. Se requiere algo más, ya 
sea la lesión de un interés extrapatrimonial diverso a esas simples molestias o bien un incumplimiento especialmente grave, ya sea por dolo o por culpa grave.

En segundo lugar, con respecto a cuáles sean esos intereses extrapatrimoniales que están protegidos por el contrato de cuenta corriente o que, dicho de otra manera, su afectación genera un daño previsible. Resultará útil una nota de cautela para comenzar. El primero de ellos es, al abrigo de dos sentencias, que hemos denominado "seguridad". La nota de cautela se justifica, en primer lugar, porque se trata solo dos sentencias. En segundo lugar, las sentencias tampoco abundan demasiado acerca de qué debe entenderse por "seguridad" en general, sino que, concretamente explican en qué consistía la obligación de seguridad del banco en cada caso. Así como en este caso:

...debía garantizar al titular que las operaciones y transacciones que éste podía realizar en forma electrónica al acceder a la página web de dicha institución financiera, mediante la digitación de su número de rol único tributario y su clave secreta, eran seguras y que ningún daño ni perjuicio patrimonial le traerían consigo. (Oscar Mahuzier García con Corpbanca, 2015, cons. 6)

No obstante lo anterior, hemos de advertir que, en un trabajo que ya hemos citado, Goldberg (1987) se refiere a la seguridad como lo denomina "Emotional Interests" (p. 85) y que nosotros denominaríamos un interés extrapatrimonial. Esta autora lo considera, predominantemente, a propósito de los contratos de seguro, sin embargo, también lo considera comprometido a propósito de un caso en que un banco pagó un cheque con firma disconforme y se negó a reembolsar el importe a la cuenta del correntista; considera que la lesión de ese interés justificaría una indemnización por daño moral en ese caso (Goldberg, 1987, p. 102).

Por lo que toca a lo que hemos denominado "libertad", también debemos aplicar una nota de cautela. Una vez más, el número de casos es muy pequeño (Oscar Mahuzier García con Corpbanca, 2015, cons. 10; y Valente Docasar Manuel / Banco Citibank N. A., 2005, cons. 5). Pero, no es únicamente esa circunstancia la que aconseja cautela. La segunda circunstancia es que, a diferencia de los casos que involucraban seguridad, ninguna de las dos sentencias referidas a la libertad la vincula con los intereses que el contrato de cuenta corriente protege.

Con todo, la innegable importancia del interés extrapatrimonial en cuestión nos lleva a pensar que el vínculo es relativamente intuitivo.

El tercer interés extrapatrimonial que, según nuestra opinión, a la luz de las sentencias presentadas, protege el contrato de cuenta corriente es el honor. Aquí, probablemente la nota de cautela no sea necesaria. Un número muy importante de sentencias lo considera, en varias ocasiones, de manera extraordinariamente explícita. Ver por ejemplo, Primera Sala Civil de la Corte Suprema (Campos Contreras, Mauricio Eugenio c. Banco Santander Chile, 2009, cons. 4); Corte de Apelaciones de Antofa- 
gasta (Dagoberto Zavala Jiménez con Banco de Crédito e Inversiones, 2015, cons. 13); Corte de Apelaciones de Concepción (Juan Luis Arellano Vaillant con Banco Santiago, 2005, cons. 15). La excepción serían la sentencia de Corte de Apelaciones de Valdivia, (Sociedad Agrícola y Forestal Casa Blanca Ltda. con Banco Santander Chile, 2001, cons. 10) y la Corte de Apelaciones de Valparaíso (Carlos González Escobar con Corpbanca, 2014 , cons. 9). Ambas, como hemos visto, no consideran que el honor esté protegido por este contrato, una por una imposibilidad legal y la otra por ser un daño imprevisible.

Sin embargo, en aras de la honestidad intelectual, hemos de advertir que varias de las sentencias no mencionan el honor, sino que se limitan a advertir que el hecho del protesto o su publicación provocan algún tipo de molestia o angustia (ver por ejemplo: Le Dantec Gallardo Enrique con Banco de Chile, 2005, cons. 8; Julio Fritz Vidal con Banco Santander Chile, 2011, cons. 19; Olivi Melendez con Banco Santander Chile, 2012, cons. 12). Nos parece, sin embargo, que no es aventurado presumir que esa molestia o angustia es experimentada precisamente porque se afecta el interés extrapatrimonial que hemos denominado "honor".

Nuestro siguiente comentario se refiere a qué han entendido los tribunales por esta expresión. Barros Bourie (2006) distingue entre el honor y la honra, el primero corresponde a una "consideración moral que tenemos de nosotros mismos" (p. 576) y la segunda corresponde "al nombre y fama en nuestros ámbitos relevantes de relación" (p. 576). Los tribunales emplean indistintamente la expresión "honor" (Ver, por ejemplo; Le Dantec Gallardo Enrique con Banco de Chile, 2005, cons. 6) y "honra" (ver, por ejemplo, sentencia de la Primera Sala Civil de la Corte Suprema; Campos Contreras, Mauricio Eugenio c. Banco Santander Chile, 2009, cons. 4) y, en un caso, estiman que lo protegido es el honor entendido en sentido subjetivo (Dagoberto Zavala Jiménez con Banco de Crédito e Inversiones, 2015, cons. 14; Campos Contreras, Mauricio Eugenio c. Banco Santander Chile, 2009, cons. 4). Creemos, entonces, que de las sentencias se desprende que tanto el honor como la honra se encuentran protegidos por el contrato de cuenta corriente.

A continuación, en las sentencias examinadas, no resulta infrecuente la mención al "prestigio comercial" (Ver por ejemplo; Juan Luis Arellano Vaillant con Banco Santiago, 2005, cons. 15; Luisa Isabel Hermosilla Bonassi con Promotora CMR Falabella S.A., 2007, cons. 30; Juan Bautista Bustos Ortega con Banco Santander Santiago, 2005, cons. 5). Sobre este punto, nos parece inadecuada la mención a propósito de una indemnización por daño moral, la razón no es que un protesto o su publicación no puedan afectar el prestigio comercial de una persona, sin duda que tiene esa aptitud. Sin embargo, según nos parece, no se trata de un daño extrapatrimonial, sino de uno patrimonial (Sobre la noción de prestigio comercial y su carácter patrimonial puede consultarse; Saidov, 2008, pp. 396-402). 
La última cuestión que quisiéramos enfatizar sobre este interés extrapatrimonial es que, si bien la mayoría de las sentencias relativas al honor resuelven casos en que ha existido publicación en algún registro público de deudores, no parece ser el caso que esta circunstancia resulte imprescindible para que se conceda la indemnización por daño moral. Creemos que esta conclusión puede justificarse no solo porque algunas sentencias conceden esta partida indemnizatoria sin la mencionada publicación (Sociedad Educacional Colegio Alemán de Arica Limitada y otra con Banco del Estado de Chile, 2011, cons. 20 ; Dagoberto Zavala Jiménez con Banco de Crédito e Inversiones, 2015, cons. 12), sino porque una sentencia indica expresamente que basta la afectación del honor en sentido subjetivo, aludiendo a que no sería necesario el desprestigio social (Dagoberto Zavala Jiménez con Banco de Crédito e Inversiones, 2015, cons. 12).

Ponemos fin a esta sección con algún breve comentario respecto a las dos sentencias que consideran que los incumplimientos del banco fueron dolosos o con culpa grave (Luisa Isabel Hermosilla Bonassi con Promotora CMR Falabella S.A., 2007, cons. 30; Banco Santander contra, 2009, cons. 10). Nos interesan este par de casos respecto a la procedencia del daño moral, porque tanto en el derecho nacional (Barros Bourie, 2006, pp. 343-344; Domínguez Hidalgo, 2000, p. 176 ; Jana Linetzky y Tapia Rodríguez, 2004, p. 192; Vidal Olivares, 2012, p. 646) como en alguno extranjero en que el precepto en cuestión es comparable al artículo 1558 del Código Civil (Morales Moreno, 2010, p. 286), se ha señalado que tratándose de este tipo de incumplimientos, las limitaciones que establece el contrato en términos de previsibilidad o de intereses protegidos se disuelven, y eso es, precisamente lo que parece querer decir la Corte Suprema en su sentencia de 3 de julio de 2007 (Luisa Isabel Hermosilla Bonassi con Promotora CMR Falabella S.A., 2007, cons. 30). De esta manera, podría señalarse que, cuando se trata de un incumplimiento doloso o con culpa grave, la pregunta acerca de si el daño moral era previsible o, formulada de otra manera, si los intereses extrapatrimoniales afectados por el contrato se encontraban protegidos por él deviene irrelevante según lo dispuesto en el artículo 1558 del Código Civil. Conviene realizar la distinción entre previsibilidad como límite y previsibilidad de la causalidad. Estimamos que la primera es la única que se torna irrelevante. Ver distinción en San Martín Neira (2013).

\section{Conclusiones}

Nos interesa concluir este trabajo resumiendo la sistematización de las sentencias que hemos intentado. Con miras a esta tarea, nos parece útil recordar las conclusiones de la doctrina más autorizada. Especialmente dos. La primera de ellas es que no todo incumplimiento contractual origina un daño moral que deba indemnizarse (Por ejemplo Domínguez Hidalgo, 2000, p. 355; Vidal Olivares, 2012, pp. 648- 
651). No obstante ciertas desviaciones, creemos que, en general, esto puede desprenderse de las sentencias.

La segunda conclusión es que, para determinar que incumplimientos lo originan debe prestarse atención a los intereses protegidos por el contrato o -en otras palabras- a la previsibilidad de ese daño moral. Al examinar las sentencias objeto de este trabajo, hemos sido capaces de identificar tres intereses extrapatrimoniales: la seguridad, la libertad y el honor u honra.

La tercera conclusión es que si el incumplimiento es doloso o con culpa grave, la pregunta acerca de la previsibilidad del daño como límite del daño moral deviene irrelevante. Nuevamente, hay que señalar que la previsibilidad como límite es la irrelevante, no la de la causalidad (San Martín Neira, 2013, pp. 553-583).

Expuestas estas tres conclusiones, quisiéramos advertir que no se nos escapa el riesgo de arbitrariedad que todo intento de sistematización entraña y, por lo mismo, hemos manifestado nuestra cautela respecto de un par de intereses extrapatrimoniales. Creemos, sin embargo, que el trabajo representa un avance sobre la procedencia de una partida indemnizatoria especialmente escurridiza en un contrato que no ha llamado particularmente la atención de la doctrina nacional.

Aunque sea objeto de otro trabajo, quisiéramos dejar apuntada nuestra perplejidad respecto de algo que si bien informamos no fue objeto de nuestra reflexión: el monto del daño moral. La cuantificación que realiza las Cortes puede llegar a ser muy dispar, así, por ejemplo, frente a la situación que el banco envía antecedentes a Dicom, en un caso estimó que la indemnización por daño moral debía ser por $\$ 30.000 .000$. (Enrique Le Dantec Gallardo con Banco de Chile, 2007, cons. 8). Por otro lado, en otro caso cuantificó la indemnización de daños extrapatrimoniales en $\$ 3.000 .000$ (Juan Luis Arellano Vaillant con Banco Santiago, 2007, cons. 8).

Para cerrar este trabajo, simplemente advertimos que nuestro intento ha sido sistematizar la opinión de los tribunales de justicia en el ámbito indicado. Esto no significa, necesariamente, que estemos de acuerdo con la forma en que han procedido.

\section{Agradecimientos}

El presente artículo se enmarca en el Proyecto Fondecyt Regular № 1161380. 
El daño moral en el contrato de cuenta corriente.

\section{Referencias Bibliográficas}

Andrés Ignacio Cifuentes Tarraza con Automotriz Rosselot SA, Rol N 1552-2014 (Corte de Apelaciones de Santiago 23 de enero de 2015). Recuperado de https://westlawchile.cl id: CL/JUR/375/2015

Aotearoa Servicios e inversiones LTDA. Con Banco de Crédito e inversiones, Rol $\mathrm{N}^{\circ}$ 859-2011 (Corte de Apelaciones de Valparaíso 26 de septiembre de 2011). Recuperado de https://vlex.cl id: 324421787

Banco Santander contra, Rol N $1870-2008$ (Corte Suprema Primera Sala Civil 7 de septiembre de 2009). Recuperado de https://westlawchile.cl id: CL/JUR/810/2009

Barros Bourie, E. (2006). Tratado de responsabilidad extracontractual. Santiago: Editorial jurídica de Chile.

Campos Contreras, Mauricio Eugenio c. Banco Santander Chile, Rol N ${ }^{\circ}$ 5795-2009 (Corte Suprema Primera Sala Civil 31 de enero de 2009). Recuperado de https://westlawchile.cl id: CL/JUR/1161/2011

Carmen Aravena Cerda con Banco de Chile, Rol No 17088-2016 (Corte Suprema Primera Sala Civil, 27 de febrero de 2017). Recuperado de https://westlawchile.cl id: CL/JUR/624/2017

Carlos González Escobar con Corpbanca, Rol № 409-2014 (Corte de Apelaciones de Valparaíso 11 de junio de 2014). Recuperado de https://westlawchile.cl id: CL/JUR/3565/2014

Cristhian Carmona Carvajal con Banco Itau, Rol No 187-2014 (Corte de Apelaciones de Antofagasta 2 de enero de 2015). Recuperado de https://vlex.cl id: 551321666

Dagoberto Ramos Sanhueza con Banco Corpbanca, Rol N 842-2013 (Corte de Apelaciones de Santiago 28 de enero de 2018). Recuperado de https://vlex.cl id: 581400946

Dagoberto Zavala Jiménez con Banco de Crédito e Inversiones, Rol N 1577-2014 (Corte de Apelaciones de Antofagasta 12 de junio de 2015). Recuperado de https://westlawchile.cl id: CL/JUR/3350/2015

Domínguez Águila, R. (2000). Responsabilidad contractual. Ausencia de daño moral. Revista de derecho (Concepción), 68(207). 173-177. Recuperado de https://bit.ly/3dEu0wy

Domínguez Hidalgo, C. (2000). El daño moral. Santiago: Editorial jurídica de Chile. 
De la Maza Gazmuri, Í. (2016). Prever y asegurar. En Universidad de Concepción, Departamento de Derecho (Ed.), M. Barría Paredes (Coord.), Estudios de derecho civil (Vol. 11, pp. 553-583). Santiago: Thomson Reuters.

Enrique Le Dantec Gallardo con Banco de Chile, Rol №3750-2007 (Corte Suprema 28 de agosto de 2007). Recuperado de https://bit.ly/3amxLEM

Enrique Miñano Zenteno con Banco Santander Chile y otro, Rol N 18821-2015 (Corte Suprema Primera Sala Civil 12 de mayo de 2016). Recuperado de https://westlawchile.cl id: CL/JUR/3233/2016

Erick Daniel Ulriksen Schmidlin con Banco de Crédito e Inversiones $\mathrm{BCl}$, Rol N ${ }^{\circ} 3056$ 2006 (Corte de Apelaciones de Concepción, 6 de enero de 2009). Recuperado de https://westlawchile.cl id: CL/JUR/8317/2009

Fischer Valenzuela, Rodrigo con Banco de Crédito e Inversiones, Rol № 14-2017 (Corte de Apelaciones de Coyhaique 18 de julio de 2017). Recuperado de https://bit.ly/2V15ehs

Franco Furlanetto Pla y otro con Inversiones y Tarjetas S.A., Rol N 1523-2014 (Corte de Apelaciones de Santiago 30 de enero de 2015). Recuperado de https://westlawchile.cl id: CL/JUR/520/2015

Gana Eguiguren, Juan Pablo con Banco Santiago, Rol N 3065-2004 (Corte de Apelaciones de Santiago 29 de abril de 2004). Recuperado de https://westlawchile.cl id: $\mathrm{CL} / \mathrm{JUR} / 2205 / 2008$

Gloria Cofian Huenchulaf con Banco Estado Chile, Rol № 97-2013 (Corte de Apelaciones de Temuco 30 de julio de 2013). Recuperado de https://westlawchile.cl id: $\mathrm{CL} / \mathrm{JUR} / 1659 / 2013$

Goldberg, C. K. (1987). Emotional distress damages and breach of contract: a new approach. U.C. Davis law review, 20(1), 57-104. Recuperado de https://bit.ly/2xtqRic

Hidalgo / Banco de Credito e Inversiones, Rol N C-2508-2011 (13 Juzgado Civil de Santiago 9 agosto 2012). Recuperado de https://bit.ly/2UGHd09

H.M., M.E. con Scotiabank Chile, Rol N²152-2013 (Corte Suprema Primera Sala Civil 23 de mayo de 2013). Recuperado de https://vlex.cl id: 438375858

H.R.P.L. con Banco de Crédito e Inversiones, Rol N 9570-2014 (Corte Suprema, Sala Primera Civil, 8 de julio de 2014). Recuperado de https://vlex.cl id: 518919686

Hugo Ruiz Ruiz con Laboratorio Biológico SA; Laboratorio de Especialidades Bionuclear SA; Laboratorio Bionuclear SA; Alejandro Guiloff Caro; Instituto de Salud Pública de Chile; Fisco de Chile, Rol N¹368-2000 (Corte Suprema 5 de noviembre de 2001). Recuperado de https://westlawchile.cl id: CL/JUR/4636/2001 
Importadora y Exportadora Sha Sha Limitada con Banco Santander Chile, Rol N ${ }^{\circ} 70-$ 2012 (Corte de Apelaciones de lquique 4 de febrero de 2013). Recuperado de https://westlawchile.cl id: CL/JUR/210/2013

Jana Linetzky, A. y Tapia Rodríguez, M. (2004). Daño moral en responsabilidad contractual a propósito de un fallo de la Corte Suprema de 5 de noviembre de 2001. Cuadernos de análisis jurídicos, 1, 171-210. Recuperado de https://bit.ly/33T1C5m

Juan Bautista Bustos Ortega con Banco Santander Santiago, Rol N 3250-2004 (Corte de Apelaciones de Concepción 19 de julio de 2005). Recuperado de https://westlawchile.cl id: CL/JUR/3133/2005

Juan Luis Arellano Vaillant con Banco Santiago, Rol N²421-2004 (Corte de Apelaciones de Concepción 3 de noviembre de 2005). Recuperado de https://westlawchile.cl id: CL/JUR/1350/2005

Juan Luis Arellano Vaillant con Banco Santiago, Rol N 6281-2005 (Corte Suprema 10 de septiembre de 2007). Recuperado de https://bit.ly/2wDDUh9

Juan Matías Silva Gaete con Central Parking System Chile S.A., Rol N 1691-2014 (Corte de Apelaciones de Santiago 19 de febrero de 2015). Recuperado de https://westlawchile.cl id: CL/JUR/1040/2015

Julián García Galleguillos con Banco del Desarrollo, Rol N³3-2010 (Corte Suprema 24 de abril de 2012). Recuperado de https://westlawchile.cl id: CL/JUR/3942/2012

Julio Fritz Vidal con Banco Santander Chile, Rol N 137-2010 (Corte Suprema 4 de julio de 2011). Recuperado de https://westlawchile.cl id: CL/JUR/10081/2011

Kim Jong Hyun con Banco Santander Chile, N 32978-2014 (Corte Suprema Primera Sala Civil 9 de septiembre de 2015). Recuperado de https://westlawchile.cl id: CL/JUR/5283/2015

Kramer, A. (2014). The law of contract damages. London: Hart.

Le Dantec Gallardo Enrique con Banco de Chile, Rol N 1735-2003 (Corte de Apelaciones de Valparaíso 6 de junio de 2005). Recuperado de https://bit.ly/2UAmtG4

Lilia Leguías Ibarra con Banco de Chile, Rol № 9355-2013 (Corte de Apelaciones de Santiago 4 de septiembre de 2014). Recuperado de https://westlawchile.cl id: $\mathrm{CL} / J U R / 10089 / 2014$

Luis Gonzaga García Ortiz con Scotiabank, Rol N 4078-2007 (Corte Suprema 14 de octubre de 2008). Recuperado de https://westlawchile.cl id: CL/JUR/6860/2008 
Luisa Isabel Hermosilla Bonassi con Promotora CMR Falabella S.A., Rol N 3901-2005 (Corte Suprema 3 de julio de 2007). Recuperado de https://westlawchile.cl id: $\mathrm{CL} / J U R / 5958 / 2007$

Mabel Cruz Muñoz con Banco Santander Chile, Rol № 69-2013 (Corte de Apelaciones de Concepción 1 de julio de 2013). Recuperado de https://westlawchile.cl id: CL/JUR/2030/2013

Manuel Valente Docasar con Banco Citibank, Rol N 1141-2006 (Corte Suprema 13 de agosto de 2008). Recuperado de https://westlawchile.cl id: CL/JUR/6089/2007

María Gloria Quintana Seguel con Banco de A. Edwards, Rol N² 293-2007 (Corte Suprema 23 de julio de 2008). Recuperado de https://bit.ly/3dzh3nt

María Rafart Moutthon con Banco de Chile, Rol №18647 (Corte Suprema 20 de octubre de 1994). Recuperado de https://westlawchile.cl id: CL/JUR/1624/1994

Mauricio Hernández Muñoz con Scotiabank Chile, N 5683-2011(Corte de Apelaciones de Santiago 3 de enero de 2013). Recuperado de https://vlex.cl id: 581519166

Méndez Soto Pablo con Banco de Chile, Rol N 8008-2011(Corte Suprema 21 de marzo de 2012). Recuperado de https://westlawchile.cl id: CL/JUR/673/2012

Meriño Figueroa, Marcos Atilio con Banco Santander Santiago, Rol No 1986-2009 (Corte Suprema Primera Sala Civil 21 de octubre de 2010). Recuperado de https://bit.ly/2yAx3Wv

Miguel Thomson San Martín con Banco Sudamericano, Rol N 6349-2002 (Corte de Apelaciones de Santiago 18 de julio de 2007). Recuperado de https://westlawchile.cl id: CL/JUR/6713/2007

Moisés Muñoz Concha con Banco Santander Chile, Rol N 915-2015 (Corte Suprema Primera Sala Civil 21 de abril de 2015). Recuperado de https://westlawchile.cl id: CL/JUR/2208/2015

Morales Moreno, A. M. (2010). Incumplimiento de contrato y lucro cesante. Cizur Menor: Thomson Reuters.

Muñoz / Banco Santander-Chile, Rol № C-2897-2011 (4 Juzgado de Letras de Talca 25 de junio 2013). Recuperado de https://bit.ly/3bQsoxl

Muñoz Concha Moisés Olivero con Banco Santander Chile, Rol N 2640-2013 (Corte de Apelaciones de Talca 29 de septiembre de 2014). Recuperado de https://bit.ly/2R4KIAO

Olivi Melendez con Banco Santander Chile, Rol N 2560-2011 (Corte Suprema 30 de marzo de 2012). Recuperado de https://westlawchile.cl id: CL/JUR/756/2012 
El daño moral en el contrato de cuenta corriente.

Oscar Mahuzier García con Corpbanca, Rol N 83-2015 (Corte de Apelaciones de Concepción 26 de junio de 2015). Recuperado de https://westlawchile.cl id: $\mathrm{CL} / J U R / 3600 / 2015$

Rol No 73-2013 (Corte de Apelaciones de Temuco 19 de junio de 2013). Recuperado de https://vlex.cl id: 641022921

Rol N 94-2013 (Corte de Apelaciones de Temuco 17 de julio de 2013). Recuperado de https://vlex.cl id: 590000718

Rol N 527-2010 (Corte de Apelaciones de Santiago 18 de mayo de 2010). Recuperado de https://westlawchile.cl id: CL/JUR/7205/2010

Rol N 1419-2009 (Corte de Apelaciones de Concepción 4 de junio de 2010). Recuperado de https://westlawchile.cl id: CL/JUR/3171/2010

Rol No 1229-2011 (Corte de Apelaciones de Santiago 26 de abril de 2011). Recuperado de https://westlawchile.cl id: CL/JUR/924/2012

Saidov, D. (2008). The law of damages in international sales: the CISG and other international instruments. Oxford: Hart.

San Martín Neira, L. (2013). La previsibilidad como límite al resarcimiento del daño por incumplimiento contractual. En S. Turner Saelzer y J. A. Varas Braun (Coord.), Estudios de derecho civil (Vol. 9, pp. 553- 583). Santiago: Thomson Reuters.

Sara Echeverría Zárate con Banco Santander Chile, Rol N 5166-2013 (Corte Suprema, 3 de junio de 2014). Recuperado de https://westlawchile.cl id: CL/JUR/4083/2014

Sebastián Soto Contreras con Banco del Estado, Rol N 92-2013 (Corte de Apelaciones de Temuco 19 de agosto de 2013). Recuperado de https://vlex.cl id: 590008054

Sociedad Agrícola y Forestal Casa Blanca Ltda. con Banco Santander Chile, Rol № 11773-2001 (Corte de Apelaciones de Valdivia 2 de octubre de 2001). Recuperado de https://westlawchile.cl id: CL/JUR/4913/2001

Sociedad Educacional Colegio Alemán de Arica Limitada y otra con Banco del Estado de Chile, Rol No 3738-2009 (Corte Suprema 25 de enero de 2011). Recuperado de https://westlawchile.cl id: CL/JUR/6128/2011

Soto con Banco Santander, Rol N 7633-1998 (Corte de Apelaciones de Santiago 1 de septiembre de 2003). Recuperado de https://westlawchile.cl id: CL/JUR/3688/2003

Testart y Cia./BBVA Bco. BHIF, Rol N²050-2004 (Quinto Juzgado Civil de Santiago 24 de noviembre de 2006). Recuperado de https://bit.ly/2UGiZIJ 
Testar y compañía Limitada /BBVA banco BHIF, Rol N 1674-2007 (Corte de Apelaciones de Santiago 18 de junio de 2009). Recuperado de https://bit.ly/3bvll6Z

Testar y Compañía Limitada c. BBVA Banco BHIF, Rol N 6456-2009 (Corte Suprema Primera Sala Civil 30 de agosto de 2011). Recuperado de https://westlawchile.cl id: CL/JUR/7323/2011

Urrutia Aguilera Eleodora con Banco Estado, Rol №3810-2012 (Corte Suprema 30 de julio de 2012). Recuperado de https://westlawchile.cl id: CL/JUR/1532/2012

Valente Docasar Manuel / Banco Citibank N. A., Rol N 1215-2000 (Corte de Apelaciones de Santiago 4 de noviembre de 2005). Recuperado de https://bit.ly/33VtEgn

Velasco Morandé Alfredo c. Corpbanca, Rol N 768-2010 (Corte de Apelaciones de Santiago 26 de octubre de 2011). Recuperado de https://westlawchile.cl id: $\mathrm{CL} / J U R / 8441 / 2011$

Vergara Cubillos Rodrigo con Latam Airlines Group S.A., Rol N 1603-2014 (Corte de Apelaciones de Santiago 27 de febrero de 2015). Recuperado de https://westlawchile.cl id: CL/JUR/1149/2015

Víctor Hugo Rivera Castro con Banco Santander Chile, Rol No 1654-2014 (Corte de Apelaciones de Antofagasta 26 de marzo de 2015). Recuperado de https://westlawchile.cl id: CL/JUR/1611/2015

Víctor Mena Lobos con Banco Santander, Rol N 16323-2016 (Corte Suprema Primera Sala Civil 31 de agosto de 2016). Recuperado de https://westlawchile.cl id: $\mathrm{CL} / J U R / 6107 / 2016$

Vidal Olivares, Á. (2012). Criterios de procedencia de la indemnización del daño moral por incumplimiento contractual. En C. Domínguez Hidalgo, J. González Castillo, M. Barrientos Zamorano y J. L. Goldenberg Serrano (Coords.), Estudios de derecho civil (Vol. 7, pp. 641-661). Santiago: Thomson Reuters.

\section{Para citar este artículo bajo Norma APA 6a ed.}

De la Maza Gazmuri, I. y Montes Serrano, N. (2020). El daño mo-

ral en el contrato de cuenta corriente: un intento de sistematización de la opinión de los tribunales. Revista de derecho (Coquim-

bo. En línea), 27, e4093, https://doi.org/10.22199/issn.0718-97532020-0002

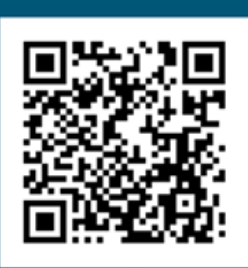

DOI

Copyright del articulo: @2020 Íñigo De la Maza y Nicolás Montes

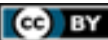

Este es un artículo de acceso abierto, bajo licencia Creative Commons BY 4.0. 